\title{
Reservoir Characterization during Underbalanced Drilling of Horizontal Wells Based on Real-Time Data Monitoring
}

\author{
Gao Li, ${ }^{1}$ Hongtao Li, ${ }^{1}$ Yingfeng Meng, ${ }^{1} \mathrm{Na} \mathrm{Wei},{ }^{1}$ Chaoyang Xu, ${ }^{1} \mathrm{Li} \mathrm{Zhu},{ }^{1}$ and Haibo Tang ${ }^{2}$ \\ ${ }^{1}$ State Key Laboratory of Oil and Gas Reservoir Geology and Exploration, School of Petroleum Engineering, \\ Southwest Petroleum University, Chengdu, Sichuan 610500, China \\ ${ }^{2}$ Engineering Supervision Center, SINOPEC Southwest Oil \& Gas Company, Deyang, Sichuan 618000, China
}

Correspondence should be addressed to Hongtao Li; lihongtao053@yahoo.com.cn and Yingfeng Meng; cwctmyf@vip.sina.com

Received 4 April 2014; Accepted 15 July 2014; Published 17 August 2014

Academic Editor: Vijay Gupta

Copyright (C) 2014 Gao Li et al. This is an open access article distributed under the Creative Commons Attribution License, which permits unrestricted use, distribution, and reproduction in any medium, provided the original work is properly cited.

\begin{abstract}
In this work, a methodology for characterizing reservoir pore pressure and permeability during underbalanced drilling of horizontal wells was presented. The methodology utilizes a transient multiphase wellbore flow model that is extended with a transient well influx analytical model during underbalanced drilling of horizontal wells. The effects of the density behavior of drilling fluid and wellbore heat transfer are considered in our wellbore flow model. Based on Kneissl's methodology, an improved method with a different testing procedure was used to estimate the reservoir pore pressure by introducing fluctuations in the bottom hole pressure. To acquire timely basic data for reservoir characterization, a dedicated fully automated control real-time data monitoring system was established. The methodology is applied to a realistic case, and the results indicate that the estimated reservoir pore pressure and permeability fit well to the truth values from well test after drilling. The results also show that the real-time data monitoring system is operational and can provide accurate and complete data set in real time for reservoir characterization. The methodology can handle reservoir characterization during underbalanced drilling of horizontal wells.
\end{abstract}

\section{Introduction}

Underbalanced drilling has been used with increasing frequency in horizontal wells as it has conspicuous technical superiorities compared to overbalanced drilling in decreasing drilling costs, preventing invasive formation damage, achieving higher rates of penetration, and reducing drilling problems such as pressure differential pipe sticking and lost circulation $[1,2]$. During underbalanced drilling the bottom hole pressure is kept below the reservoir pore pressure. As a result the reservoir will transport fluids towards the wellbore, generating a transient well influx during drilling. The influx behavior of reservoir fluids depends on the pressure difference between the reservoir pore pressure and the bottom hole pressure and reservoir permeability and porosity, in addition to other reservoir parameters such as the viscosity and compressibility of reservoir fluids. The transient well influx causes flow behavior variations in the wellbore. Owing to the changes in well fluid composition and well fluid flow rates, the transient influx of reservoir fluids causes variations in the flow in the wellbore. Analogous to well testing and transient reservoir analysis, the reservoir characteristics close to the well causing the influx might be identified on site by monitoring some of the fluid flow data of the well, such as pressure changes and rate changes $[3,4]$. This is the principal idea that also is the basis for reservoir characterization during underbalanced drilling. Estimation of the near wellbore characteristics of the formation gives important information for planning well completion design, well pressure control, and optimizing drilling parameters on site such as the well's horizontal length, gas injection volume, and orientation.

Reservoir characterization during underbalanced drilling still needs strong theories to be formulated with reliable smart experiments. The complexity of this subject arises from the fact that the boundary conditions of transient well inflow change with time during the test and that the rates of transient well influx are influenced by variation in underbalance. 
Moreover, the exhaustive and reliable monitoring data are not easy to be acquired in real time. To the best of the authors' knowledge, the idea that reservoir characterization while underbalanced drilling was first presented by Kardolus and van Kruijsdijk [5] in 1997. In their paper, a transient reservoir influx model of a vertical well under a constant underbalance based on the boundary element method was developed. They compared the model with a transient analytical reservoir model and demonstrated that the transient analytical reservoir model could be used for evaluating characteristic parameters in the reservoir, in particular the permeability. In a following study, van Kruijsdijk and Cox [6] developed a method for identifying the permeability profiles along the well trajectory of a horizontal well considering the variable underbalance and the more complex outer boundary conditions of a horizontal well.

Reservoir characterization during underbalanced drilling has been investigated by several other researchers in recent years. Larsen and Nilsen [7] proposed a simple quasistationary model for predicting the inflow at various levels of complexity and accuracy for spreadsheet and calculator applications based on drilling speed and knowledge of the ratio of vertical to horizontal permeability. The influx predictions calculated by their model and a numerical reservoir simulator were compared, giving a good agreement. AzarNejad [8] presented a model for influx predictions using the discrete flux element method. In his study, he mentioned factors affecting influx rates and indicated that the solutions of model are very sensitive to the reservoir thickness. Hunt and Rester $[9,10]$ developed and solved new reservoir models describing the underbalanced drilling problem and characterizing the dynamic changes in single layer and multilayered reservoirs. They also presented a history matching method for predicting the reservoir permeability. Biswas et al. [11] proposed a genetic search algorithm for identifying the reservoir characterization, accounting for storage effects in both the wellbore and reservoir. In a paper by Vefring et al. [3], a transient reservoir model coupled to a transient wellbore flow model was used. They estimated the reservoir properties using novel Levenberg-Marquardt algorithm, a nonlinear least-squares optimization method. In a followup research [4], the ensemble Kalman filter was also used to predict reservoir pore pressure and reservoir permeability while applying active tests and compared with the LevenbergMarquardt algorithm. A paper by Kneissl [12] presented a method of simultaneously deriving reservoir pore pressure and permeability profiles in real time during underbalanced drilling by introducing fluctuations in the bottom hole pressure during drilling. However, the variations of fluid flow behavior in the wellbore might pose difficulties in estimating the influx rates, which may lead to large uncertainties in the estimate of reservoir pore pressure [13]. Stewart et al. [14] proposed an integrated transient model of the formation and the wellbore based on superposition. The method of matching the cumulative production data for estimating permeability using iterative search was also developed in their paper. However, an assumption that the pore pressure is known independently was made analogously like most of above researchers. The problem at hand is complex [11].
Although many models and methods for identifying reservoir characterization while underbalanced drilling have been proposed, the interpretation of reservoir properties is difficult in real reservoirs, particularly in real time, except for the simplest cases.

This paper describes a new pursuit of the complex problem of identifying the reservoir characterization during underbalanced drilling of horizontal wells. A model of transient well influx of horizontal wells is used together with a multiphase wellbore flow model. The effects of the density behavior of drilling fluid and wellbore heat transfer during underbalanced drilling are considered in our wellbore flow model. Based on the Kneissl's methodology, an improved method of estimating reservoir pore pressure performed by introducing fluctuations in the bottom hole pressure by manipulating the choke valve opening and changing fluid composition or pump rates is presented in this paper. An effort is also made to monitor accurately and automatically measurements required for reservoir characterization in real time.

The paper is organized by first presenting the real-time data monitoring. Then the transient wellbore flow model and transient well influx model are presented, respectively. Based on the data monitoring and mathematical models, we then propose the methodology for estimating reservoir characterization. In this paper, the reservoir pore pressure and permeability profiles are the main reservoir properties needed to be characterized. The methodology is then applied to a realistic case, and results are discussed. Thereafter, a conclusion is made.

\section{Real-Time Data Monitoring}

The accurate and automatic acquisition of basis data in real time has been a challenge for reservoir characterization during drilling of horizontal wells, which is crucial and is a prerequisite. During a standard underbalanced drilling operation, lots of indispensable parameters can be recorded by the compound logging and other measuring equipment, such as the density and rheology of the drilling fluid, well depth, penetration rate, pump pressure, outlet rates, trajectory of the well, and wellbore diameter. However, these measurements are insufficient and not accurate enough for reservoir characterization. Being more pivotal, most of these measurements cannot be acquired in real time, which is indispensable to identifying reservoir characterization during drilling. This paper has presented a dedicated fully automated control real-time data monitoring system, based on the integration and modification of existing devices or components and the installation of some more indispensable sensitive and accurate measuring instruments. In addition to installing some measuring equipment monitoring indispensable parameters for reservoir characterization unrecorded generally in conventional drilling, the data from compound logging and PMWD/MWD are involved in our realtime monitoring system. It is believed that the integration is also beneficial for well control and drilling parameter 
optimization in underbalanced operations. The measurements of interest here are as follows:

(i) injection and outlet drilling fluid densities,

(ii) injection and outlet drilling fluid rates,

(iii) drilling fluid viscosity,

(iv) oil outlet rates and density,

(v) penetration rate in the formation,

(vi) injection and outlet gas rates, pressure, and temperature,

(vii) outlet gas component,

(viii) standpipe and surface casing pressure,

(ix) bottom hole pressure,

(x) measured depth and wellbore diameter,

(xi) BHA and hole trajectory,

(xii) formation porosity.

Schematics of the location of the real-time data monitoring system with respect to the well for aerated drilling and liquid-based underbalanced drilling are illustrated in Figures 1 and 2, respectively. In order to explain the data monitoring systems clearly, it is necessary to first introduce the circulation process for underbalanced drilling. During aerated drilling operations, drilling fluid from mud pits and nitrogen from gas injection system consisting of compressor, nitrogen generator, and booster are mixed and injected into the drill strings under pressure via a fluid line, as shown in Figure 1. The gasified drilling fluid is then circulated out with the produced formation fluid through the annulus into the primary flow line and enters the separator where gas and oil are separated. The drilling fluid returns to the mud pits via a return line after taking out the solids using shale shakers. Produced oil is sent to an oil shimming tank. Separated gas is sent to a combustion cell. For liquid-based underbalanced drilling, the circulation process is somewhat different because only drilling fluid is injected, as shown in Figure 2. Thus, the measurements of the gas injection rates, pressure, and temperature were not involved in the data monitoring system for liquid-based unbalanced drilling. For the reason that the attenuation of drilling fluid pulse in multiphase flow restricts the use of down hole measuring devices with transmission medium of drilling fluid pulse in aerated drilling $[16,17]$, PMWD/MWD data were not included in the data monitoring system for aerated drilling.

As shown in Figures 1 and 2, the real-time data monitoring systems consist of various kinds measuring instruments, an incoherent receptor, a signal converser, and a PC. To acquire various parameters in different types in real time, the measuring facilities used here include pressure transducers, temperature transducer, gas and liquid flowmeters, density measuring unit, and portable gas analyzer. The strong technology and sophisticated equipment were applied in data acquisitions in this paper. The pressure transducers used here have a frequency response of $0.1 \sim 1000 \mathrm{~Hz}$ and a maximum full scale output error of $0.75 \%$ FSO over the 0 to $70^{\circ} \mathrm{C}$ compensated range. The injection and outlet gas temperature was measured by the temperature transducers with wide temperature range from $-55^{\circ} \mathrm{C}$ to $+150^{\circ} \mathrm{C}$ and excellent linearity of $\pm 0.3^{\circ} \mathrm{C}$. In order to assure measurement accuracy, different types of portable type clip ultrasonic flowmeter were clamped on to the existing pipeline to acquire, respectively, the drilling fluid, oil, and gas rates. The density measuring unit proposed by Carlsen et al. [18], consisting of three pressure transducers placed along the circulating path from the pump to the connection to the drill string, was used to identify automatically the injection drilling fluid density. An advantage of this method is that it enables automatic updates of the density. Likewise, the outlet drilling fluid density can readily be determined. The density of outlet oil was measured using a common method for the reason that it is relatively fixed for a particular reservoir. The acquisition of outlet gas component can be completed using a portable gas analyzer. One of the technical superiorities of this system is that a digital microwave transmission technique was used to transmit the data recorded by various measuring equipment instead of the use of the cable. All the measuring instruments shown in Figures 1 and 2 were attached to a wireless radiated element, respectively. Measurement signals from pressure transducers, flowmeters, and other instruments were received wirelessly by an incoherent receptor and then analyzed and recorded using a signal analyzer after being converted into digital signals. It is noted that the incoherent reception technique indicated in Spalding and Middleton [19] was applied here to tackle the reception of signals in the impulsive interference environment. Data acquisition software called LabVIEW was used to capture the measurement signals. These measurements together with compound logging data and PMWD/MWD data were preprocessed to detect necessary information for reservoir characterization in standard data formats using MATLAB on a personal computer. Owing to the use of wireless transmission technique, the signal receptor and data processing system no longer have to be located near the well site, which makes remote supervisory and technical service possible. The work above in this paper ensures that the data are accurate, real time and easily available, which is critical and considerable for reservoir characterization during drilling.

\section{Transient Wellbore Flow Model}

The wellbore transients have significant effect on actual well inflow and therefore should be considered in reservoir characterization. The real-time data monitoring system can provide bottom hole pressure in liquid-based underbalanced drilling. During aerated drilling, the wellbore transients must be calculated by mathematical means owing to the serious attenuation of PMWD signals. In this section a onedimensional liquid-gas two-phase transient model governing wellbore flow with thermal effects in aerated drilling is developed, with variables resolved in the axial direction only. Besides, the effect of the cutting bed in horizontal sections is considered. Owing to complexity of the liquid-gas two-phase flow transient in wellbore, the following assumptions made for the model development are primarily given. 


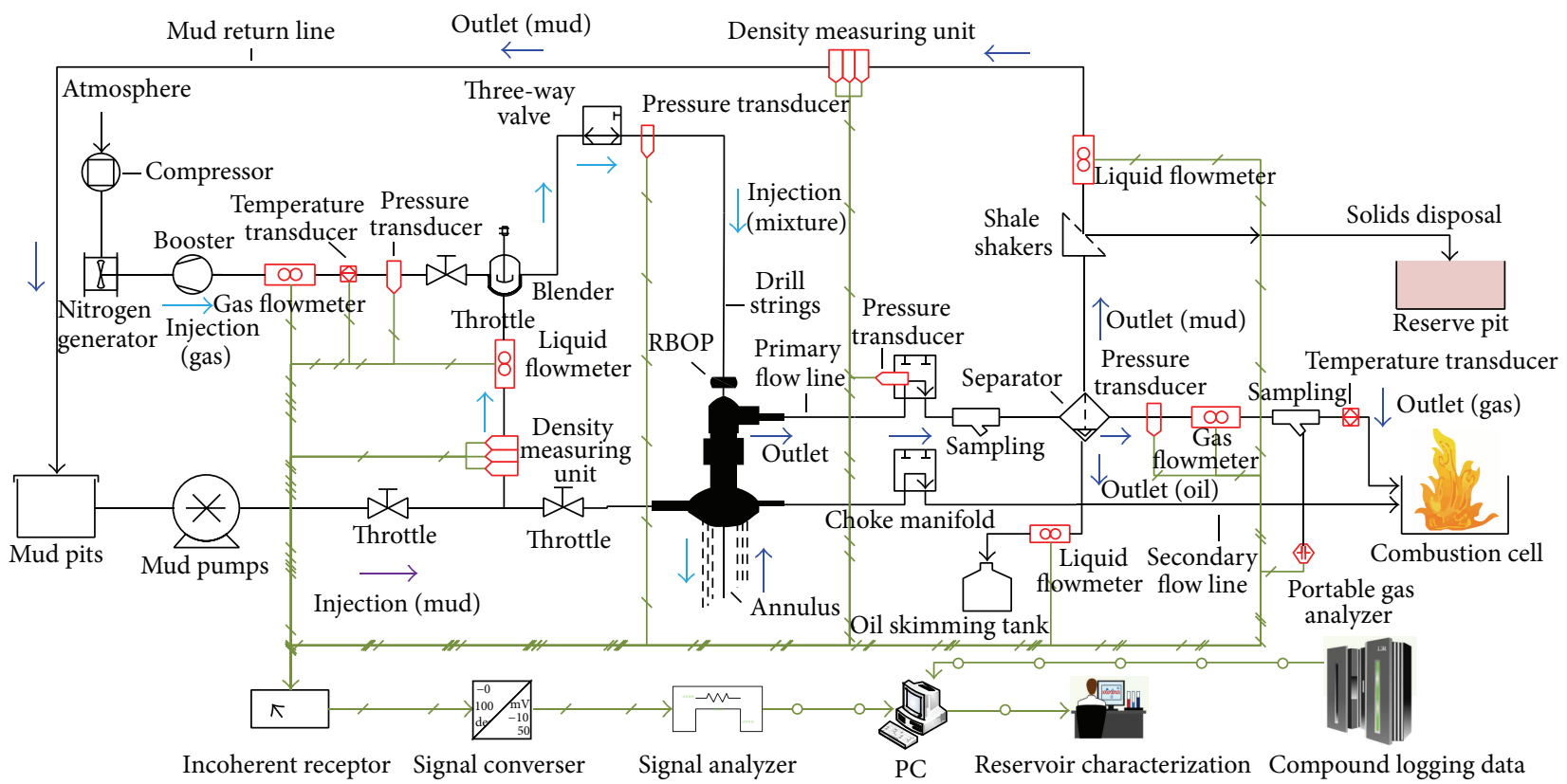

FIGURE 1: A schematic of the placement of the real-time data monitoring system for aerated drilling.

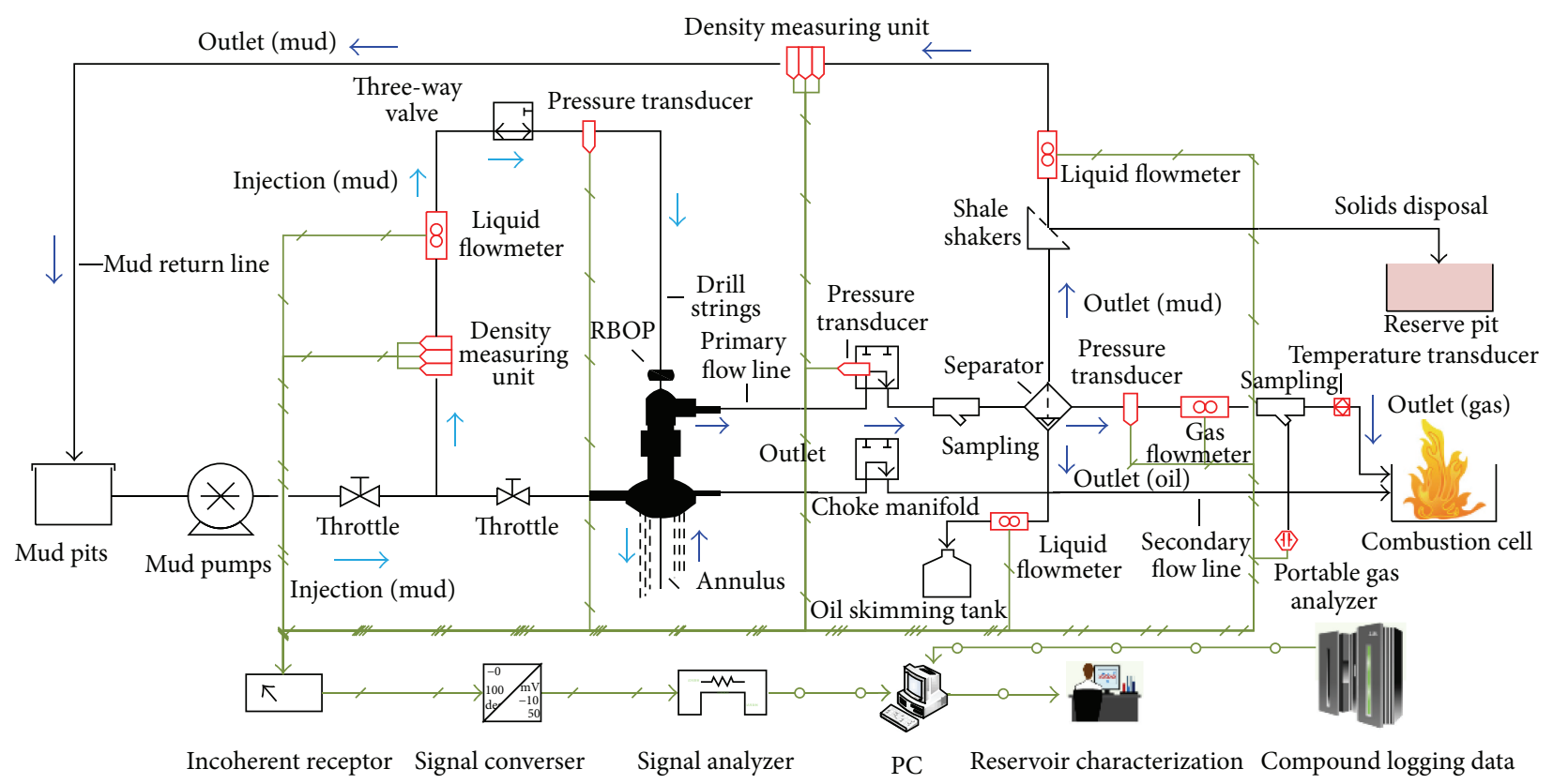

FIGURE 2: A schematic of the placement of the real-time data monitoring system for liquid-based underbalanced drilling.

(i) The liquid phase fluids are incompressible and Newtonian.

(ii) Properties of fluids are uniform and constant.

(iii) The bubbles are spherical in shape having diameter as the characteristic.

(iv) The transverse lift force is neglected.

(v) The turbulent dispersion force of gas phase is neglected. (vi) The effects of breakup and coalescence of droplets and bubbles are neglected.

(vii) Mass transfer effects are neglected.

3.1. Model Development. In this paper, a transient model of liquid-gas two-phase flow in wellbore is proposed on the basis of the three-dimensional model, averaged in time and space given by Lahey and Drew [20]. The governing equations consist of continuity equations for each component and a 
momentum conservation equation. Such equations can be written as follows:

gas continuity equation

$$
\frac{\partial\left(\rho_{g} \alpha_{g}\right)}{\partial t}+\frac{\partial\left(\rho_{g} \alpha_{g} u_{g}\right)}{\partial z}=0
$$

liquid continuity equation

$$
\frac{\partial\left(\rho_{l} \alpha_{l}\right)}{\partial t}+\frac{\partial\left(\rho_{l} \alpha_{l} u_{l}\right)}{\partial z}=0
$$

gas momentum conservation equation

$$
\begin{aligned}
& \frac{\partial\left(\rho_{g} \alpha_{g} u_{g}\right)}{\partial t}+\frac{\partial\left(\rho_{g} \alpha_{g} u_{g}^{2}\right)}{\partial z}+\alpha_{g} \frac{\partial p}{\partial z} \\
& =-\alpha_{g} \rho_{g} g \sin \theta-F_{d g}-F_{v m}-F_{w g}
\end{aligned}
$$

liquid momentum conservation equation

$$
\begin{aligned}
& \frac{\partial\left(\rho_{l} \alpha_{l} u_{l}\right)}{\partial t}+\frac{\partial\left(\rho_{l} \alpha_{l} u_{l}^{2}\right)}{\partial z}+\alpha_{l} \frac{\partial p}{\partial z} \\
& \quad=-\alpha_{l} \rho_{l} g \sin \theta-F_{d g}-F_{v m}-F_{w l}
\end{aligned}
$$

where $p$ is pressure, $g$ is the acceleration due to gravity, $\rho$ is density, $u$ is velocity, $\alpha$ is the volumetric fraction, $\theta$ is the deviation angle, $t$ and $z$ are temporal and spatial coordinates, $F_{d}$ is drag force, $F_{v m}$ is virtual mass force, $F_{w}$ is wall shear force, and the subscripts $g, l$ represent gas and liquid, respectively. The indispensable closure relationships appearing in equations above are formulated and described in Appendix A.

Due to the mixture of gas-liquid two phases, the distribution relation of two-phase homogeneous fluid can be normalized as

$$
\alpha_{g}+\alpha_{l}=1
$$

In this paper, gas phase can be deemed as the ideal gas and can be evaluated using the equation of state in the following manner:

$$
p=Z \rho_{g} R T
$$

where $T$ is temperature, $R$ denotes the gas constant, and $Z$ is the real gas deviation factor, which is the function of pressure, temperature, and the nature of the gas.

In the transient liquid-gas two-phase flow model, the heat transfer between wellbore and formation is considered by introducing a wellbore heat transfer model during twophase flow presented by Hasan and Kabir [21] based on a rigorous energy balance equation for two-phase flow [22]. An expression for fluid temperature in wellbore as a function of well depth and producing time is primarily given by

$$
\begin{aligned}
T= & T_{e i}+\xi\left[1-e^{H / \xi}\right]\left(\frac{g}{g_{c}} \frac{\sin \theta}{J C_{p}}+\varphi+g_{T} \sin \theta\right) \\
& +e^{(H-z) / \xi}\left(T_{f b h}-T_{e b h}\right)
\end{aligned}
$$

where $T_{e i}$ is undisturbed formation temperature at given depth, $\xi$ is inverse relaxation distance, $H$ is total well depth from surface, $g_{c}$ and $J$ represent conversion factors, $C_{p}$ is the mean heat capacity of the multiphase fluid at constant pressure, $g_{T}$ is geothermal temperature gradient, $\varphi$ is parameter combining the Joule-Thompson and kinetic energy effects, $T_{f b h}$ is fluid temperature at the bottom hole, and $T_{e b h}$ is formation temperature at bottom hole. Some important parameters are discussed in detail in Appendix B.

In the transient wellbore flow model, we consider the density behavior of drilling fluid under high pressure and high temperature conditions during underbalanced drilling operation. A more accurate analytical model for densitypressure-temperature dependence for drilling fluid in drilling proposed by Karstad and Aadnoy [23] was presented in the following manner:

$$
\rho_{l}=\rho_{l s f} e^{\gamma_{p}\left(p-p_{s f}\right)+\gamma_{p p}\left(p-p_{s f}\right)^{2}+\gamma_{T}\left(T-T_{s f}\right)+\gamma_{T T}\left(T-T_{s f}\right)^{2}+\gamma_{p T}\left(p-p_{s f}\right)\left(T-T_{s f}\right)}
$$

where $\rho_{l s f}$ is the drilling fluid density under standard conditions, $T_{s f}$ is the standard temperature, $\rho_{s f}$ is the standard pressure, and the values of $\gamma_{p}, \gamma_{p p}, \gamma_{T}, \gamma_{T T}$, and $\gamma_{p T}$ are essentially unknown and must be determined for different muds from density measurements at elevated pressures and temperatures.

Though we have made an assumption of gas liquid twophase flow in wellbore, the effect of cutting bed in horizontal well on wellbore flow simulation has to be considered. The cutting bed existing in the horizontal annulus reduces the open flow area of gas liquid two-phase fluid, which is a critical factor in wellbore flow simulation. In this paper, we consider the effect of cutting bed by evaluating the open flow area of gas liquid two-phase fluid in horizontal annulus causing the movement of cutting bed. The cuttings transport in horizontal wellbore has been investigated by many researchers [24-30]. In this paper, we use a mechanics model with aerated drilling fluid proposed by Zhou [30] to predict the movement of cutting bed and the cutting bed height.

3.2. Numerical Solution. In order to solve the model, the finite difference technique, which is one of the most widely used numerical methods, is applied in this paper. The technique is implemented by replacing all derivatives by difference quotients. Owing to the introduction of analytical expression of temperature, the model is easier to solve using 
the technique. Discretization of governing equations can be obtained applying a first order downstream implicit scheme for time derivations. For the stability of numerical solutions, the donor cell concept is used. The fluid exit conditions are assumed to be the same as the fluid conditions in the node itself. The discretized form of governing equations can be written in the following matrix form:

$$
\mathbf{D}_{j}\left(\mathbf{v}_{j}^{0}\right) \mathbf{v}_{j}^{t+\Delta t}=\mathbf{E}_{j}\left(\mathbf{v}_{j}^{0}, \mathbf{v}_{j}^{t}, \mathbf{v}_{j-1}^{t+\Delta t}\right),
$$

where $\mathbf{D}$ is the coefficient matrix, $\mathbf{E}$ is the independent vector, $j$ is cell number, the superscripts $t$ and $t+\Delta t$ are the dependent variables calculated at the old and new times, respectively, the superscript 0 represents the dummy variables for the iterative method, and $\mathbf{v}$ is a column vector of dependent variables given as follows:

$$
\mathbf{v}=\left(p, \alpha_{g}, u_{g}, u_{l}\right)^{T}
$$

where the superscript $T$ indicates the transpose.

Mechanistic models for two-phase flow in drill string and annuli [31-33] are used to provide the necessary information for numerical calculation about flow patterns, pressure drops, phase volumetric fractions, and phase velocities in each old time node. The wellbore fluid temperature at each grid point can be estimated using (7). In this paper, we use the algorithm based on the factorization of a matrix using a version of the Gaussian elimination with partial pivoting.

It is important to note that the numerical solution is transient due to the fact that almost all the transient terms are considered in our model. In addition, the numerical solution of two-phase wellbore flow under constantly changing flowing environmental can be given easily owing to the establishment of real-time data monitoring system.

\section{Transient Well Influx Model}

In underbalanced drilling, the transient well influx can be deemed as a complex well test. The complexity arises from the fact that the boundary conditions vary with times in value and type during the test because the well is continuously increasing in length. In the drilled part of the reservoir we have a Dirichlet boundary condition. Instead, the Neumann boundary condition is dealt with along the future well trajectory in the reservoir. Also keep in mind that the transient influx rates are influenced by variation in underbalance and penetration rate. Therefore, the traditional well test techniques are not fit for the purpose of modeling transient well influx during underbalanced drilling. Because of the complexity of the problems, a realistic model is needed to predict the transient well inflow while drilling.

4.1. Mathematical Model. The model in this paper represents a simplification of the actual reservoir. It is assumed that the reservoir is symmetric around the well and possesses constant reservoir and parameters. During the transient period, we assume that there is no pressure response from the border of the reservoir. For transient flow of a single phase, the governing differential equation can be given in the form of diffusivity equation:

$$
\nabla^{2} p=\frac{\phi \mu c}{k} \frac{\partial p}{\partial t}
$$

where $\phi$ is porosity, $c$ is reservoir compressibility, $\mu$ is the viscosity of reservoir fluid, and $k$ is the reservoir permeability.

With the above assumption that there is no pressure response from the border of the reservoir, the outer boundary is given in the following Neumann manner:

$$
\frac{\partial p}{\partial n}=0
$$

where $n$ is the normal of the boundary surfaces.

Essentially, the main difference of transient influx during drilling with convention well test operations lies in the inner boundary, which changes with time. For the part of the reservoir penetrated by a horizontal well, we have a Dirichlet boundary condition:

$$
p=p_{w h}
$$

where $p_{w h}$ is the pressure at bottom hole.

For the undisturbed part of the reservoir, the influx rates are zero; in other words, the inner boundary conditions likewise can be captured by the above Neumann manner. It is important to note that as a result of the continuous increase in well length the inner boundary conditions do not only change in value but in types as well. Every drill step the part of the reservoir that is dominated by the Neumann condition decreases, while the zone governed by the Dirichlet condition increases. This means that we have to deal with a new set of equations with different boundary conditions for every step drill step. Thus, we are in dire need of new realistic expression to describe the transient well influx during underbalanced drilling.

4.2. Approximate Analytical Solution. To allow analytical solutions of the transient influx problem, some essential hypotheses are made in this paper. We assume that the reservoir consists of a number of independent elements or zones as shown in Figure 3. It is assumed that the fluid flows along planes perpendicular to the well. During underbalanced drilling, a new zone is added to the well every step in time. The size of the time step and the thickness of drilled zones must conform to the penetration rate, which is considered to be constant here. It is assumed that production from new added zone starts at the moment when it is being penetrated by drilling. The total production rate at a given time can be obtained by adding the production response of individual zones that time. Thus, the total production rate as a function of time can be given by

$$
q_{t o t}(t)=\int_{0}^{z(t)} q_{w}(z, t) d z
$$




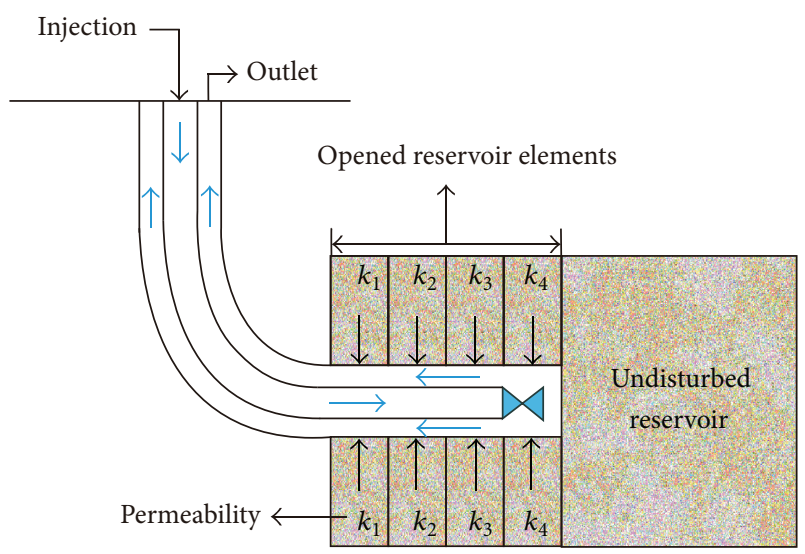

FIGURE 3: A schematic of a horizontal well drill into the reservoir consists of a number of independent elements.

where depth, $z$, is a function of time, $t$, and the penetration rate, $u_{p}$, and $q_{w}(x, t)$ is the well influx from a unit thickness. Substitution of $d z=u_{p} d t$ yields

$$
q_{t o t}(t)=\int_{0}^{t} q_{w}(z, \tau) u_{p} d \tau
$$

Using Duhamel's theorem, van Kruijisdijk and Cox [6] proposed that the transient well influx for a given element can be rendered to a convolution of the underbalance and the time derivative of the well influx for a constant and unit underbalance and rewrote the above equation in the following manners:

$$
q_{\text {tot }}(t)=\int_{0}^{t} u_{p} \int_{\tau}^{t} \frac{\partial\left(p_{r e s}-p_{w}(\zeta)\right)}{\partial \zeta} q_{w u}(\Theta, t-\zeta) d \zeta d \tau,
$$

where $q_{w u}(t)$ denotes the unit-underbalanced inflow of unit reservoir segment at the given time, $\Theta$ represents the set of reservoir parameters that define the flow geometry and properties, $p_{\text {res }}$ is the reservoir pore pressure, and $p_{w}$ is a function of time and is defined as

$$
p_{w}(t)= \begin{cases}p_{\text {res }} & \text { for } t \leq t_{\text {open }}(z) \\ p_{w h}(t) & \text { for } t>t_{\text {open }}(z) .\end{cases}
$$

The function $t_{\mathrm{open}}(z)$ represents the time at which the drill bit penetrates point $z$, thereby opening that point along the well trajectory up to flow.

To obtain an analytical solution of transient well inflow at any given time, we need a realistic expression of the unitunderbalance transient inflow of each unit thickness segment $q_{w u}(t)$. Based on the appropriate source functions in Laplace space, van Kruijisdijik [34] proposed the following analytical solution:

$$
q_{w u}(t)=\frac{2 \pi k h}{\mu B_{o}} \frac{a_{1} /\left(\pi r_{w}\right)}{S_{z}+a_{2} \sqrt{k t / \phi \mu c r_{w}^{2}}}
$$

where $h$ is the reservoir thickness, $r_{w}$ is the radius of the wellbore, $B_{o}$ is the volume factor of the reservoir fluid, $S_{z}$ is the effective skin due to vertical flow, $a_{1}$ and $a_{2}$ are the coefficient and have, respectively, the values of 0.611 and 1.083 in the early time of transient influx.

For gas reservoir, the expression of the transient inflow is a bit different from (16), the analytical solution for oil reservoir proposed by van Kruijisdijk and Cox [6]. The compressibility of gas decides the influx difference between oil and gas reservoir. We define the pseudopressure as follows:

$$
\dot{m}=2 \int_{p_{0}}^{p} \frac{p}{\mu_{g}(p) Z(p)} d p,
$$

where $p_{0}$ is the known pressure for reference, $\mu_{g}$ is the gas viscosity, and $Z$ is the compressibility factor of the gas. Then, the total influx rates of gas reservoir during underbalanced drilling can be given:

$$
q_{t o t}(t)=\int_{0}^{t} u_{p} \int_{\tau}^{t} \frac{\partial\left(\dot{m}_{r e s}-\dot{m}_{w}(\zeta)\right)}{\partial \zeta} q_{w u}(\Theta, t-\zeta) d \zeta d \tau .
$$

Analogously, we rewrite the analytical expression of $q_{w u}$ for gas reservoir in the following manner:

$$
q_{w u}(t)=\frac{\pi k h}{B_{g}} \frac{Z_{s c} T_{s c} \rho_{g s c}}{p_{s c} T} \frac{a_{1} /\left(\pi r_{w}\right)}{S_{z}+a_{2} \sqrt{k t / \phi \mu c r_{w}^{2}}},
$$

where the subscript denotes the standard state.

\section{Methodology of Estimating Reservoir Characterization}

After establishing data monitoring system in real time, a transient liquid-gas two-phase flow model in wellbore and well influx model during drilling have been derived. Hereunto, we have reliable data acquisition approach and theoretical model for reservoir characterization. In this section, let us focus on specific approach to estimate reservoir properties. At first we will propose a new methodology to acquire reservoir pore pressure and then discuss how to extract the reservoir permeability profiles during drilling.

5.1. Reservoir Pore Pressure. Inspired by the interesting methodology of identifying reservoir pore pressure proposed by Kneissl [12], a new improved method of testing reservoir pore pressure is developed using different testing procedure, avoiding the uncertainties affected by variations of fluid flow behavior in the annulus sections and unpredictable inflow of new added zones. It is noted that the idea of identifying reservoir pore pressure by actively fluctuating the bottom hole pressure is still the key kernel thought of our method. Focusing on the new methodology, a principal assumption has to be made that the reservoir drilled consists of different zones with constant formation pressure coefficient, which corresponds with the most common circumstances. With the continuous pressure system assumption, it is easy to 
obtain reservoir pore pressure of each zone by extracting the reservoir pressure coefficient when the reservoir is opened. This greatly simplifies the procedure of pore pressure test and avoids complex mathematical computation usually used in other methods. To eliminate the uncertainties of estimate results introduced by continuous inflow of new zones, it is needed to stop drilling but keep circulation to begin the testing operation when the first reservoir zone was opened, which is the difference from Kneissl's method in testing procedure. Taking into account the fact that only the first zone was opened in the testing operation, the transient inflow of well can be given by

$$
q_{w}(t)=\frac{2 \pi k h\left(p_{r e s}-p_{w}(t)\right)}{\mu B_{o}} \frac{a_{1} /\left(\pi r_{w}\right)}{S_{z}+a_{2} \sqrt{k t / \phi \mu c r_{w}^{2}}} .
$$

It can be rewritten as

$$
\frac{q_{w}(t)}{p_{\text {res }}-p_{w}(t)}=\frac{2 \pi k h}{\mu B_{o}} \frac{a_{1} /\left(\pi r_{w}\right)}{S_{z}+a_{2} \sqrt{k t / \phi \mu c r_{w}^{2}}} .
$$

At very short time, the expression reduces to the following manner:

$$
\begin{aligned}
\lim _{t \rightarrow 0} \frac{q_{w}(t)}{p_{\text {res }}-p_{w}(t)} & =\lim _{t \rightarrow 0} \frac{2 \pi k h}{\mu B_{o}} \frac{a_{1} /\left(\pi r_{w}\right)}{S_{z}+a_{2} \sqrt{k t / \phi \mu c r_{w}^{2}}} \\
& =\frac{2 \pi k h}{\mu B_{o}} \frac{a_{1} /\left(\pi r_{w}\right)}{S_{z}},
\end{aligned}
$$

which is entirely independent of the time and the down side of the equation can be considered constant for a given reservoir. It also can be interpreted that the transient inflow of well has a significant negative linear correlation with the pressure at bottom hole in the earliest hours of inflow. For the inflow of well to become zero, the reservoir pore pressure is approached by the pressure at bottom hole. Thence, we can identify the reservoir pore pressure by searching for the linear correlation between the inflow and pressure at bottom at the early stage of transient inflow. This process is performed by introducing artificially fluctuations in the bottom hole pressure and by measuring the inflow rates and bottom hole pressure based on the real-time data monitoring system. For aerated drilling, the bottom hole pressure can be estimated using the transient wellbore flow model mentioned in this paper. Figure 4 illustrates some details concerning how to extract the reservoir pore pressure. Here, linear fitting of some measurement points is used to identify the linear correlation between the well inflow and bottom hole pressure, and the reservoir pore pressure can be read at the crossing of the best-fit regression line and the horizontal axis. For the reliability of test results, the number of testing points should not be less than three. Fluctuations of the bottom hole pressure can be introduced by managing the choke valve, changing gas injection rates or pump rates. To eliminate the effects of variations of fluid flow in the wellbore on the estimated results, it is necessary to leave enough time to capture relative steady inflow rates for each fluctuating

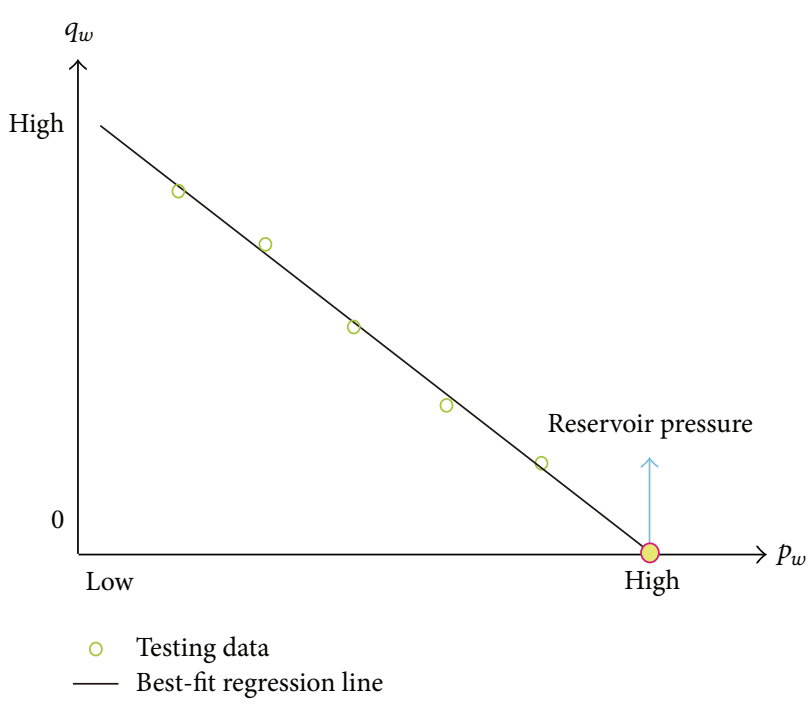

FIGURE 4: Reservoir pore pressure test by introducing fluctuation at the bottom hole pressure.

operation, and the time needed lasts for a few minutes or more than one hour, which depends on well depth, the type of operations introducing the fluctuation in the bottom hole pressure, reservoir characteristics such as permeability and formation fluid properties, and so on.

Having acquired the reservoir pore pressure of the first zone when the reservoir is opened, the reservoir pressure coefficient and pressure of subsequent zones can be obtained during drilling using a simple formula. For the case where more than one reservoir with different pressure system was drilled, new testing procedure should be repeated when new reservoir was opened. The only difference is that the inflow measurements consist of the transient inflow response of the former reservoir and the transient well inflow of new reservoir's first zone. Here, necessary mathematical treatment of the inflow measurements is needed.

5.2. Permeability Profiles. To determine the reservoir permeability, we make the simplifying assumption that the permeability is constant in specified zones of the well. Transient influx from each reservoir zone with different permeability at the time of interest constitutes the total production rates of the well, which can be got from the real-time data acquisitions system. The analytical expressions of total production rates and unit-underbalance response of each zone which are related to the permeability have been established in the last section of this paper. The reservoir pore pressure of each reservoir zone can be calculated after testing the reservoir pressure coefficient just when the reservoir was opened. It is assumed that the porosity, reservoir height, and other reservoir parameters apart from permeability are constant and known. Theoretically, the permeability of each reservoir zone can be easily determined using (18) and (21). Unfortunately, the analytical expressions of the total production rates are given in integral form, which results in that they cannot readily be implemented in spreadsheet and calculator 
applications. To facilitate the calculation, a full discretization of the total production rates formula is given instead of the integral form in the following manner:

$$
q_{\text {tot }}(t)=u_{p}\left(p_{r e s}-p_{w}\right) \sum_{i=1}^{n=t / \Delta t} q_{w u i}\left(\Theta_{i}, t-t_{i}\right) \Delta t,
$$

where $\Delta t$ represents the time needed to penetrate through a reservoir element, which is constant with the assumption of the fixed penetration rate, $q_{w u i}\left(\Theta_{i}, t-t_{i}\right)$ denotes unitunderbalanced inflow of unit reservoir segment from zone $i$, and $t_{i}$ denotes the time the wellbore reaches zone $i$. The value of $q_{w u i}\left(\Theta_{i}, t-t_{i}\right)$ for nonpositive arguments is set equal to 0 .

The above discretization equation was given on the basis of a reasonable assumption that we have a constant underbalance, which is realistic and is of engineering significance for underbalanced drilling of a horizontal well.

First, we discuss how to extract the permeability of the 1 st reservoir zone. The total production rates from the realtime monitoring system at the first time step when reservoir is opened can be simply considered to be the influx from the first zone. Then, we have the following formula:

$$
\begin{aligned}
q_{t o t}\left(t_{1}\right) & =q_{w 1}\left(t_{1}\right) \\
& =u_{p} \Delta t\left(p_{\text {res }}-p_{w}\right) q_{w u 1}\left(\Theta_{1}, t_{1}\right) \\
& =u_{p} \Delta t\left(p_{r e s}-p_{w}\right) \frac{2 \pi k_{1} h}{\mu B_{o}} \frac{a_{1} /\left(\pi r_{w}\right)}{S_{z}+a_{2} \sqrt{k \Delta t / \phi \mu c r_{w}^{2}}}
\end{aligned}
$$

Solving the equation above, $k_{1}$, the permeability of the 1st reservoir zone can be given as follows:

$$
k_{1}=\left(m_{2} q_{w 1}\left(t_{1}\right) \sqrt{\Delta t}+\sqrt{m_{2}^{2} q_{w 1}^{2}\left(t_{1}\right) \Delta t+\frac{q_{w 1}\left(t_{1}\right) S_{z}}{m_{1}}}\right)^{2},
$$

where

$$
m_{1}=\frac{2 u_{p} \Delta t\left(p_{r e s}-p_{w}\right) h a_{1}}{\mu B_{o} r_{w}}, \quad m_{2}=\frac{a_{2}}{2 m_{1} r_{w} \sqrt{\phi \mu c}} .
$$

Analogously, well influx from the reservoir element $i$ can be given:

$$
\begin{aligned}
& q_{w i}\left(t_{1}\right) \\
& =q_{t o t}\left(t_{i}\right)-\sum_{n=1}^{i-1} q_{w n}\left(t_{i-n}\right) \\
& =q_{t o t}\left(t_{i}\right)-u_{p} \Delta t\left(p_{r e s}-p_{w}\right) \sum_{n=1}^{i-1} q_{w u n}\left(t_{i}-t_{n}\right) \\
& =u_{p} \Delta t\left(p_{r e s}-p_{w}\right) \frac{2 \pi k_{i} h}{\mu B_{o}} \frac{a_{1} /\left(\pi r_{w}\right)}{S_{z}+a_{2} \sqrt{k_{i} \Delta t / \phi \mu c r_{w}^{2}}}
\end{aligned}
$$

where $q_{\text {tot }}\left(t_{i}\right)$ represents the total production rates of the well at time $t_{i}$ when the reservoir element is opened; $q_{w u n}\left(t_{i}-t_{n}\right)$ denotes the unit-underbalance transient influx response of unit thickness reservoir from reservoir zone $n$ at time $t_{i}$ and can be given using (21).

Then, we can extract the permeability of the reservoir zone $i$ by

$$
k_{i}=\left(m_{2} q_{w i}\left(t_{1}\right) \sqrt{\Delta t}+\sqrt{m_{2}^{2} q_{w i}^{2}\left(t_{1}\right) \Delta t+\frac{q_{w i}\left(t_{1}\right) S_{z}}{m_{1}}}\right)^{2} .
$$

Using the methodology, the permeability of a set of reservoir zones can be successively extracted as the reservoir is being penetrated by a horizontal well. To facilitate the precise calculation and estimate permeability profiles in time, a computer procedure was used in this paper. The success of reservoir permeability estimation profits from reliable realtime data monitoring system, advanced wellbore flow and reservoir model, and an innovative reservoir pore pressure test approach.

\section{Results and Discussion}

The methodology presented in this paper has been used to identify the reservoir pore pressure and permeability profiles of approximately 10 wells during underbalanced drilling in China. In order to illustrate the above approach in detail, an actual horizontal well and gas reservoir are considered in this section. It is appropriate to emphasize that the well picked as case study is the first successful application of this methodology. More exhaustive data and offset information from this well facilitate the effectiveness evaluation of this method. The reservoir dealt with here is the Ordovician carbonate gas reservoir with natural fractures as the dominant gas storage spaces and flowing channels. To avoid lost circulation and formation damage, the well is drilled underbalanced using the aerated clay-free drilling fluid, while this is also beneficial for well control. Here, nitrogen is used as the injection gas. The hole geometry and drilling assembly of this well were illustrated in Figure 5. Some basic parameters for reservoir and drilling fluid used in reservoir characterization were shown in Table 1.

6.1. Data Acquisition in Real Time. The real-time data monitoring system for aerated drilling presented in this paper was used to acquire basic data for reservoir characterization in real time. The application of this system guarantees that the indispensable parameters are accurate and timely, which makes it possible to identify reservoir characterization. During drilling, this system succeed in the integration of the data from compound logging and our sensitive measuring instruments, and the digital microwave transmission was proved to be realizable and reliable to deliver wirelessly data. Some typical acquired measurements plotted against time are shown in Figures 6-10. In order to illustrate the transient behavior for different parameters, the measuring time for different parameters in figures differs. The standpipe 


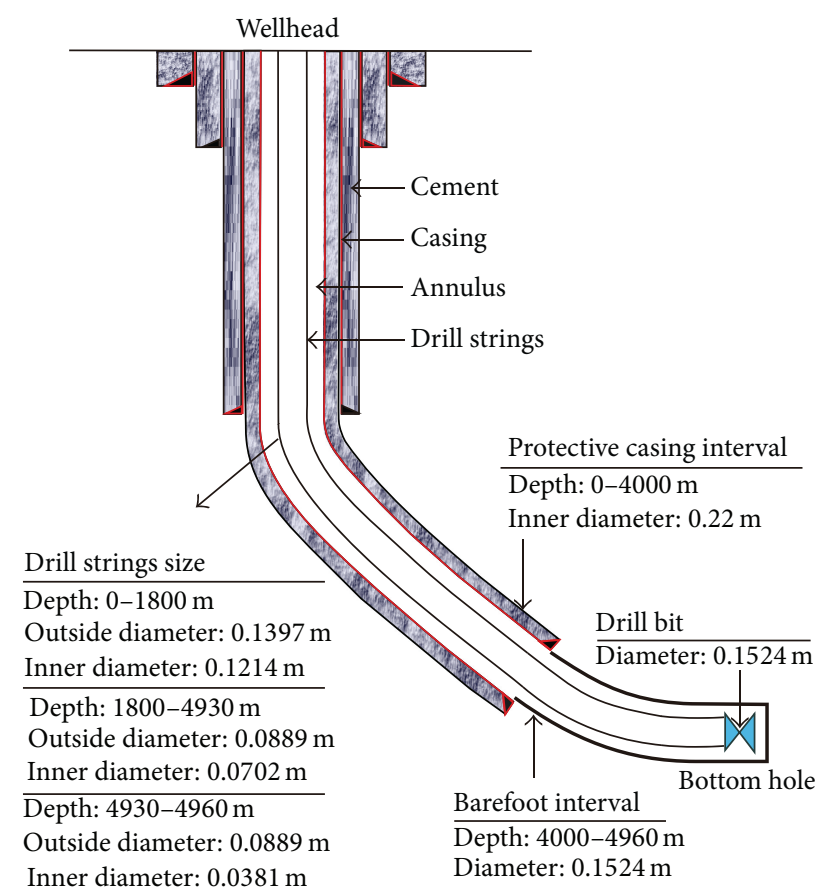

FIGURE 5: The hole geometry and drilling assembly of the well.

TABLE 1: Basic parameters for reservoir and drilling fluid used in reservoir characterization.

\begin{tabular}{|c|c|}
\hline Depth evaluation of the reservoir, $\mathrm{m}$ & 4156 \\
\hline Reservoir thickness, $\mathrm{m}$ & 15 \\
\hline Porosity, \% & 12 \\
\hline Reservoir fluid volume factor, $\mathrm{m}^{3} / \mathrm{std} . \mathrm{m}^{3}$ & 0.008 \\
\hline Reservoir fluid viscosity, $\mathrm{mPa} \cdot \mathrm{s}$ & 0.035 \\
\hline Reservoir compressibility, $\mathrm{Pa}^{-1}$ & $1.16 \times 10^{-9}$ \\
\hline Reservoir fluid compressibility, $\mathrm{Pa}^{-1}$ & $11.77 \times 10^{-9}$ \\
\hline Geothermal temperature, $\mathrm{K} \cdot \mathrm{m}^{-1}$ & 0.03 \\
\hline Drilling fluid density at standard conditions, $\mathrm{g} \cdot \mathrm{cm}^{-3}$ & 1.04 \\
\hline Drilling fluid viscosity at standard conditions, $\mathrm{mPa} \cdot \mathrm{s}$ & 20 \\
\hline Injection gas specific gravity, 1 & 0.97 \\
\hline Injection gas viscosity at standard conditions, $\mathrm{mPa} \cdot \mathrm{s}$ & 0.019 \\
\hline
\end{tabular}

pressure and casing pressure for different time are plotted, respectively, in Figures 6 and 7. It can be seen that the transient fluctuations of standpipe pressure are more acute than that of casing pressure. In general, this difference can be aroused by unsteady drilling fluid and gas injection, check calve, measuring apparatus installed along drill string, and drill string vibration. The casing pressure changing with time in Figure 7 indicates the different outlet gas rates or varied choke opening. Figure 8 shows the drilling fluid density as a function of time for outlet and injection, respectively. Contrary to the standard drilling operations, more accurate and automatic measurements of drilling fluid density can be obtained in real time, utilizing instrumented standpipe and separator drilling fluid outlet pipe using different pressure

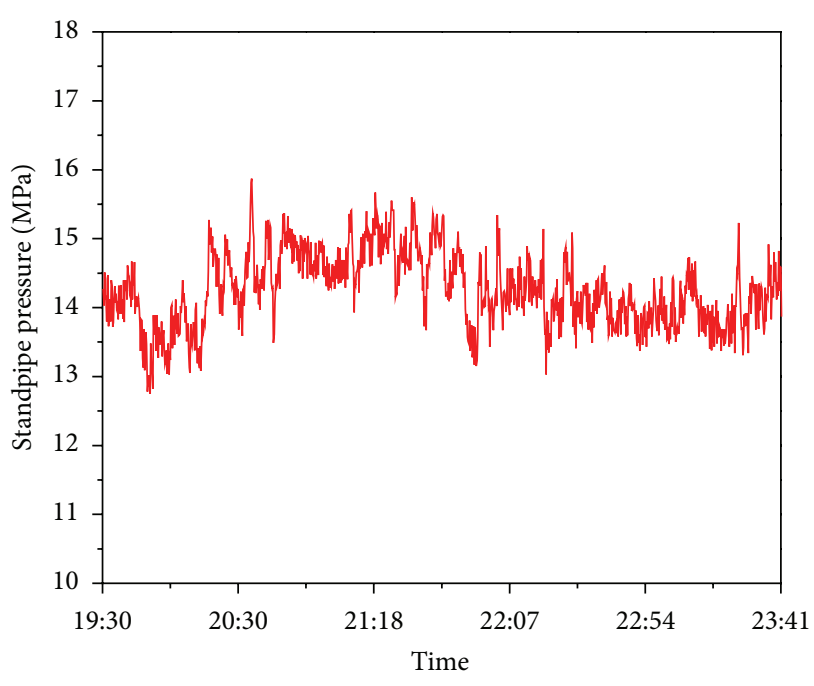

FIGURE 6: Data acquisition-standpipe pressure data versus time (2010-9-27).

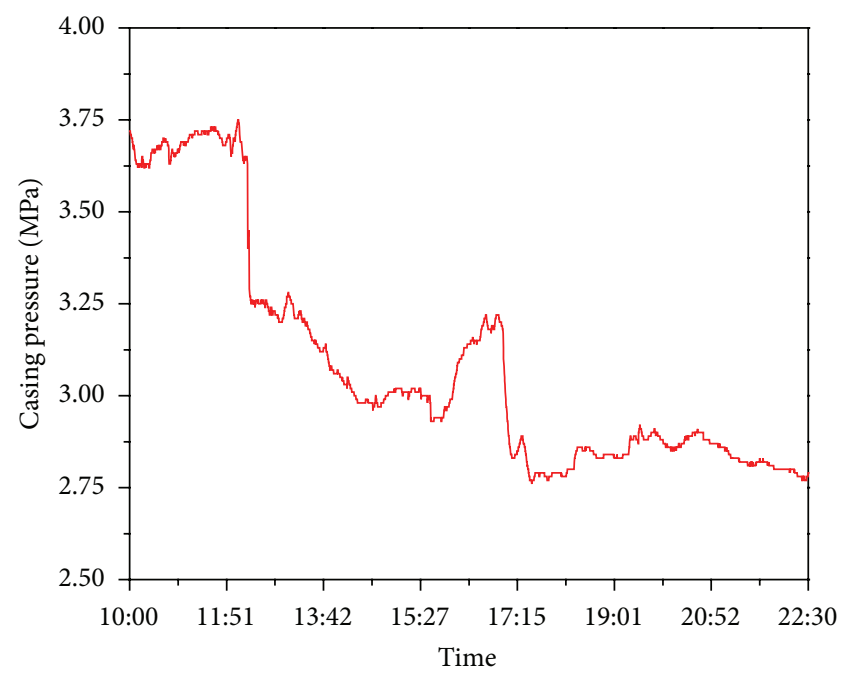

FIGURE 7: Data acquisition—casing pressure data versus time (20109-27).

transducers, not measured manually in intervals of $15 \mathrm{~min}$ utes. It is noted that the outlet drilling fluid density is slightly lower than that of injection fluid and fluctuates wildly. This transient behavior of outlet drilling fluid density occurs as a result of varied outlet gas rates and nonthorough degassing of drilling fluid. In this study, we monitor the total hydrocarbon content of outlet gas and outlet gas rates to acquire the reservoir gas inflow rates in real time. The measured outlet gas rates and reservoir gas inflow rates are presented in Figure 9. The real-time reservoir gas inflow rates, absolutely critical for reservoir characterization, are calculated using the outlet gas rates and total hydrocarbon content in time of interest as shown in Figure 10. In sum, the application of the new real-time data monitoring system in this well helps drilling contractor with good underbalanced drilling operations and 


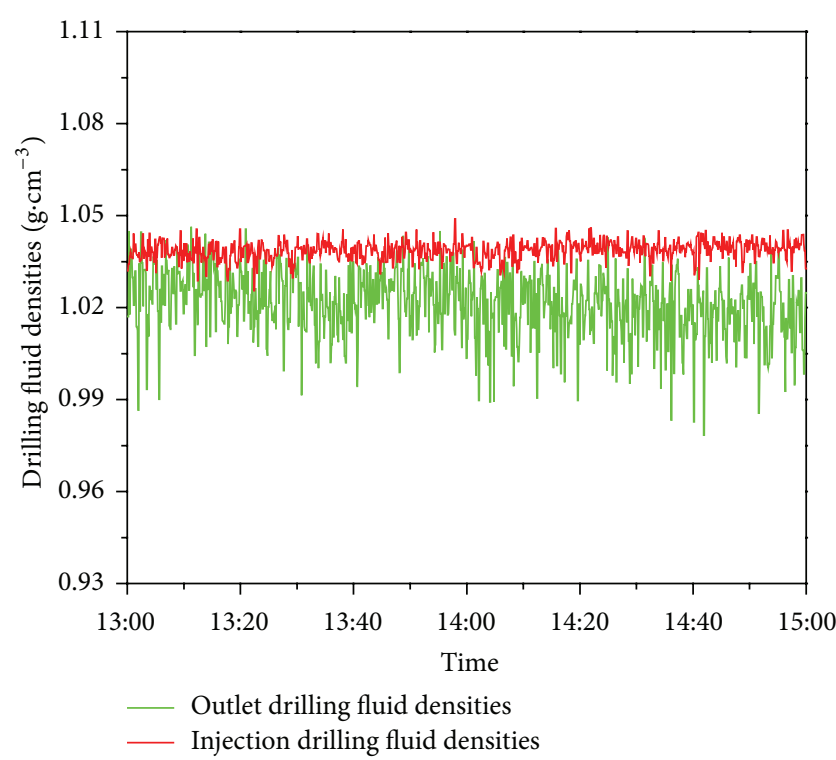

Figure 8: Data acquisition-drilling fluid density data versus time (2010-9-25).

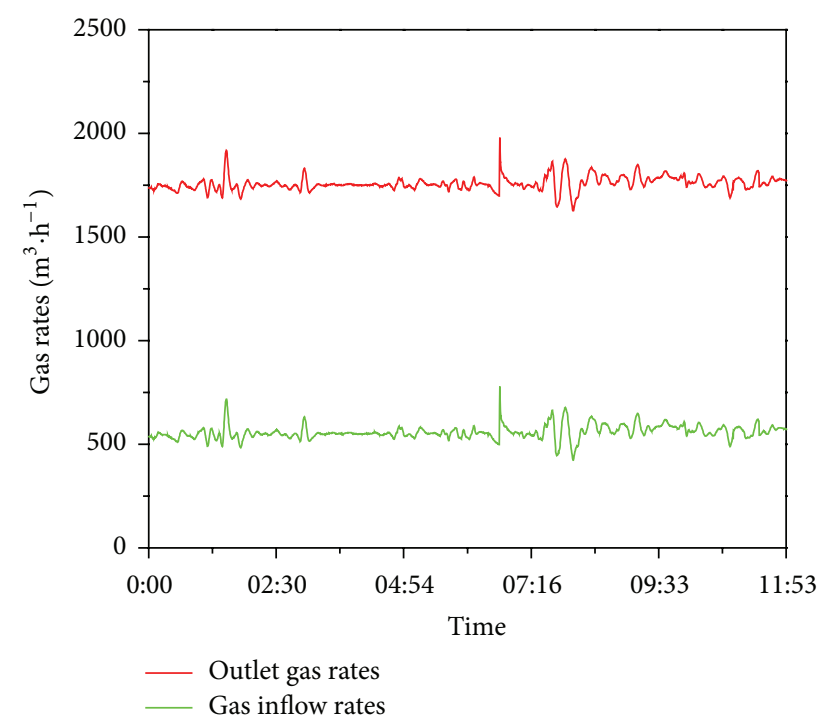

FIGURE 9: Data acquisition-outlet gas rates and gas inflow rates data versus time (2010-9-25).

provides accurate and more complete data set in real time for reservoir characterization during drilling.

6.2. Reservoir Characterization. In this paper, the reservoir characterization we are interested in refers to the reservoir pore pressure and reservoir permeability. It is assumed that the reservoir dealt with here consists of a number of different zones, each $1 \mathrm{~m}$ in thickness. With each zone, the reservoir pore pressure and permeability are constant. In this section, we discuss the details of identifying the reservoir pore pressure and permeability and their comparison with the actual data.

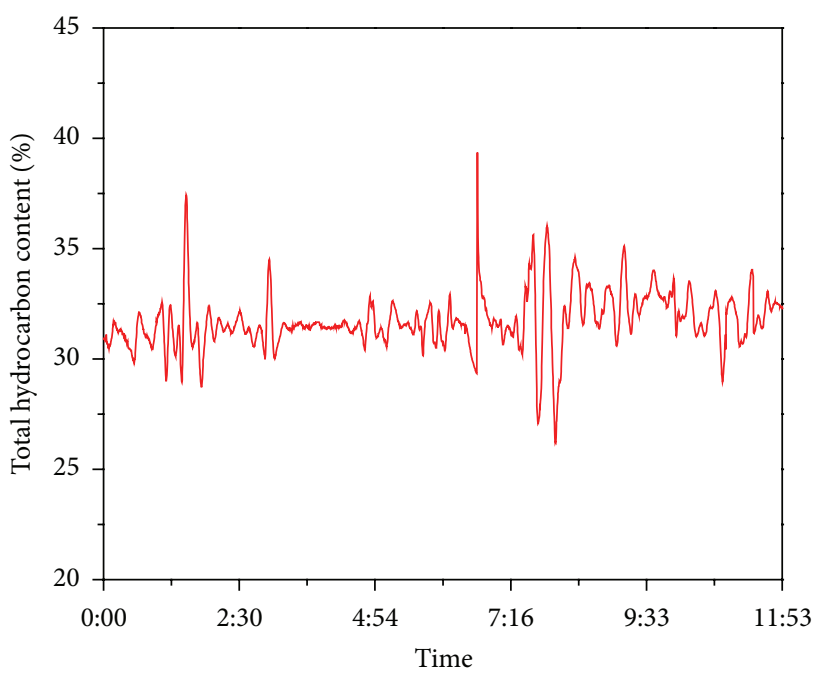

FIGURE 10: Data acquisition-total hydrocarbon content data versus time (2010-9-25).

For this well, the reservoir was opened at the well depth of $4880 \mathrm{~m}$ when visible gas inflow was detected for the first time. And then we stopped drilling but kept circulation to begin the reservoir pore pressure test procedure. Here, the fluctuations of the bottom hole pressure were introduced by manually accommodating the choke valve, without drilling fluid and gas injection changes. After trying for some times, three testing points with relative steady inflow lasts for more than one hour were observed and illustrated in Figure 11. For aerated drilling used in this well, the bottom hole pressure for three testing points can be estimated using the transient wellbore flow model. The important input parameters in the wellbore flow simulation such as surface casing pressure, outlet gas and drilling fluid rates, and outlet drilling fluid density were provided by the data monitoring system shown in Figure 1 in real time. For the three testing points, the time-averaged gas inflow rates and bottom hole pressure and their best-fit regression line are plotted in Figure 12. With the fitted regression equation in Figure 12, it is easy to extract the reservoir pore pressure for the first zone to be $41.91 \mathrm{MPa}$. Having known the vertical depth of $4139.7 \mathrm{~m}$ when the test was conducted, the reservoir pressure coefficient can be obtained to be 1.032, which meets very closely the actual value of 1.03 obtained from well-test data after drilling. The measured inclination at the well depth of 4870 before beginning underbalance drilling operation is $88.5^{\circ}$. For aerated drilling, the hole inclination cannot be measured in real-time with the use of MWD. It is appropriate to make the assumption that we have the same hole inclination for the underbalance drilling interval with length of $80 \mathrm{~m}$. Considering the case here that the reservoir with consistent pressure system was drilled by a horizontal well, it is easy to obtain the reservoir pore pressure profile of the well, as shown in Figure 13. It is noted that we use the actual reservoir pressure coefficient from well-test data after drilling. Thus, the good match between the estimated reservoir pressure and actual data indicates the feasibility 


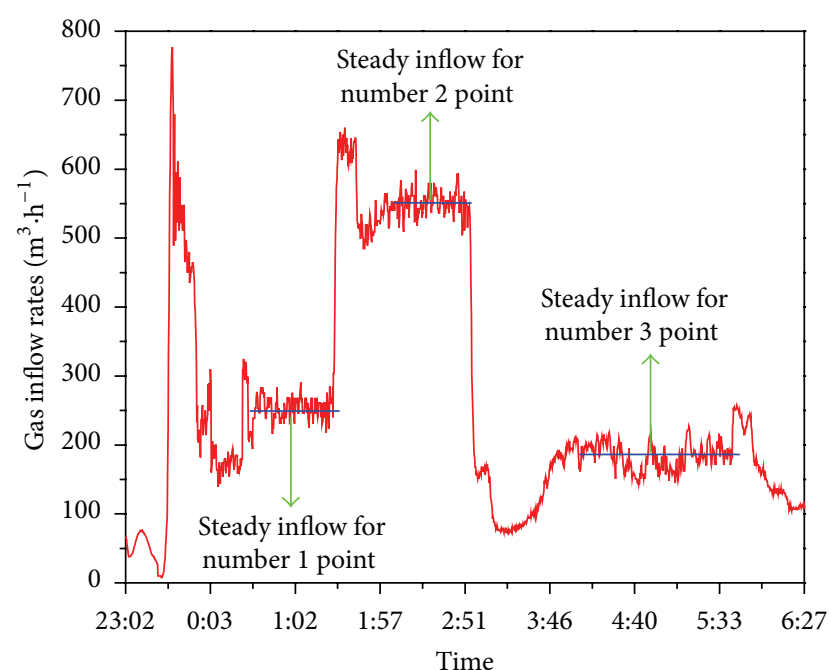

FIGURE 11: Three segments of steady inflow obtained by introducing fluctuation at the bottom hole pressure.

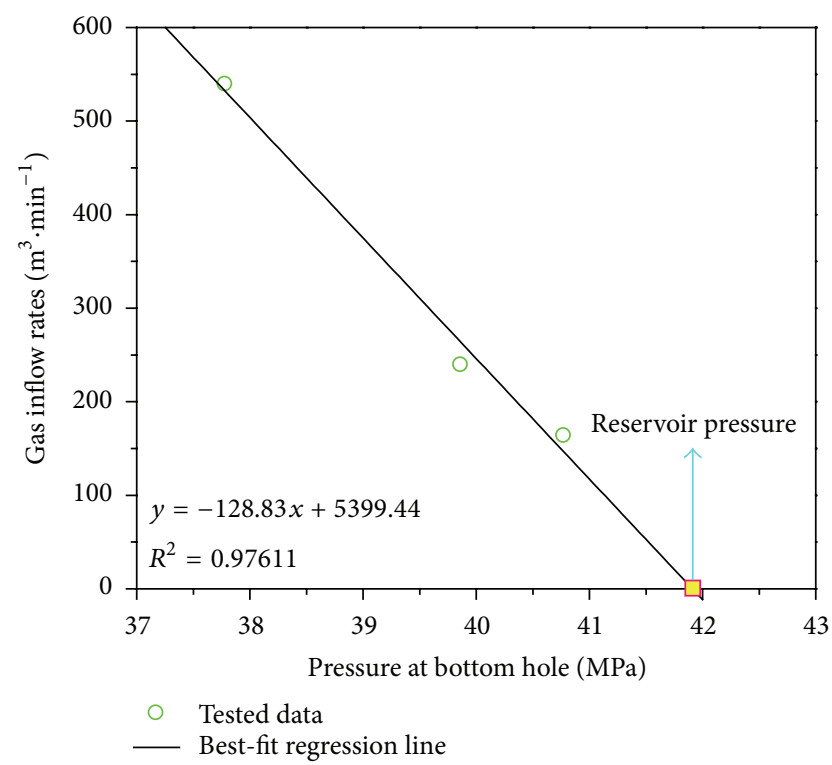

Figure 12: Gas inflow rates versus pressure at bottom hole and the best-fit regression line.

and reliability of the reservoir pressure test methodology presented in this paper.

Having obtained the reservoir pore pressure profile, we can extract the permeability of every zone from real-time monitoring data using the methodology presented in this paper. To be candid, this is not a simple event. For every zone, complex mathematical computations are required to identify permeability. Some necessary mathematical equations needed for computation have been mentioned in the above section in this paper. Basic parameters for reservoir and drilling fluid and the hole geometry and drilling assembly of the well required for reservoir characterization have been given in Table 1 and Figure 5, respectively. The data monitoring system provided the real-time data required such

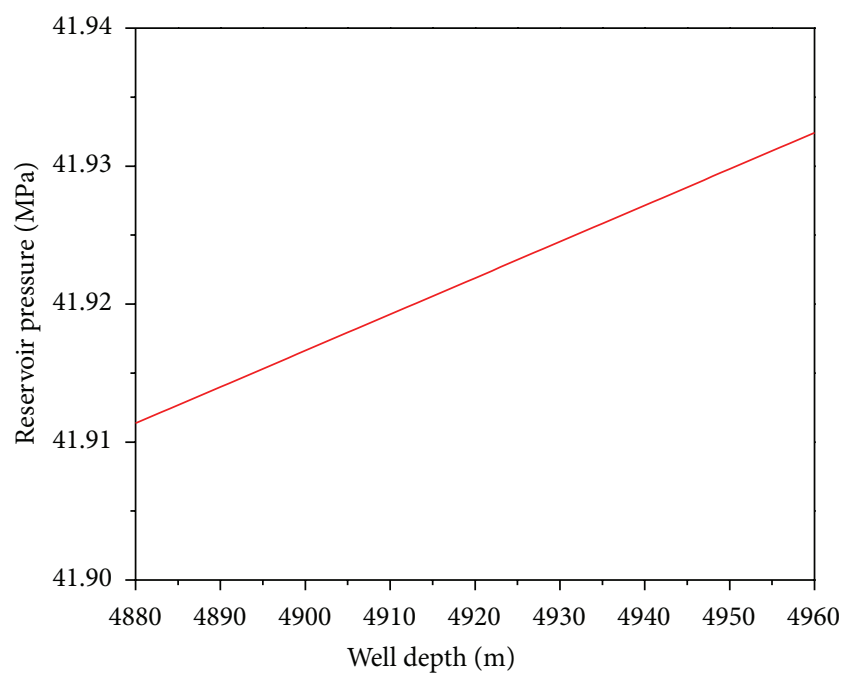

FIGURE 13: Reservoir pore pressure profile estimated using the improved methodology.

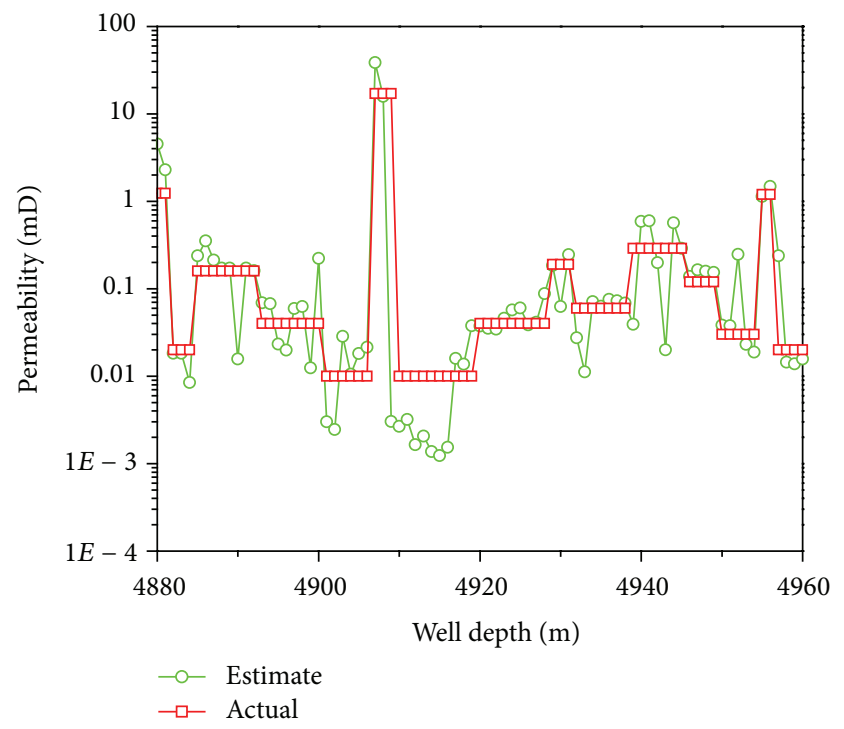

FIGURE 14: A comparison between estimated and actual permeability profiles.

as casing pressure, injection and outlet gas rates, injection and outlet drilling fluid density, and injection drilling fluid rates, when performing reservoir characterization for every zone. The estimated and actual permeability profiles are indicated in Figure 14 and show a good agreement in magnitude on the whole. However, we observe that there is a difference between the estimated and actual values of the permeability for different zones. In this example, the actual permeability was obtained using the multi-interval test after drilling and given in the form of average value for every interval. To be different from the actual permeability, the separate permeability of every unit reservoir thickness was estimated by dividing the reservoir into discrete zones with thickness of $1 \mathrm{~m}$, which is an outstanding originality of the methodology 


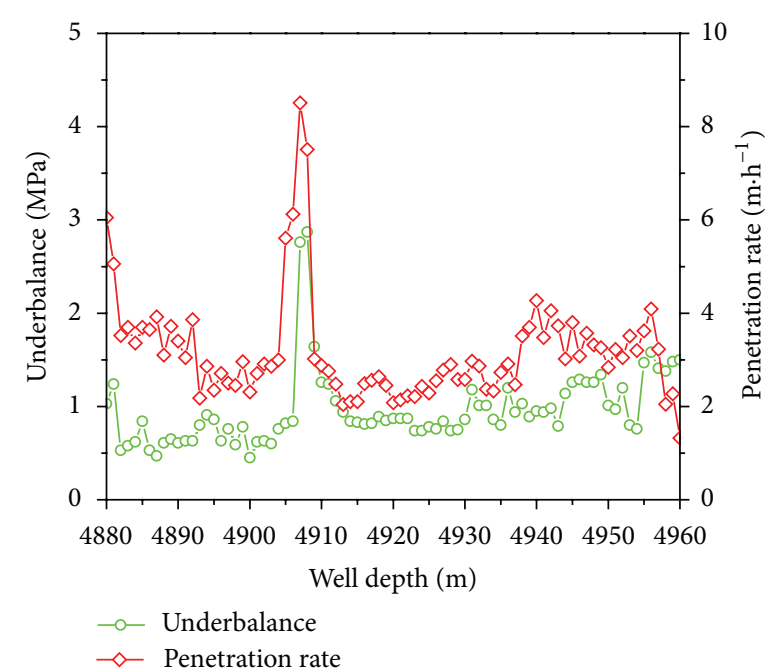

FIGURE 15: Underbalance and penetration rates profiles.

presented in this paper. This is the major element causing the difference between the estimated and actual permeability profiles in Figure 14. Beyond this, it is also observed that the quality of the reservoir characterization varies in different zones. The unconstant underbalance and penetration rate shown in Figure 15 might result in the difference. In this paper, the mathematical expressions estimating the reservoir permeability were derived with the constant underbalance and penetration rate assumption. The variable penetration rates and underbalance cause the results that the estimated permeability are slight less accurate than those obtained with constant penetration rates and underbalance [6]. Besides, the estimated results of the near zones opened subsequently are also affected. However, the quality of the reservoir characterization is still acceptable. Low underbalance and penetration rates are a benefit when performing characterization, which are also important for the well control. In the drilling practice, the penetration rates are easy to control, but it is hard to keep constant underbalance and penetration rate through all the process, and the only thing we could do was to restrict the variation of the underbalance. In order to validate the reservoir characterization method proposed in this study, the gas simulated outlet rates at a time when a high permeable zone was penetrated at a depth of $4907 \mathrm{~m}$ were compared in Figure 16 with the monitoring data. The estimated permeability for different reservoir zones at depths from $4880 \mathrm{~m}$ to $4907 \mathrm{~m}$ shown in Figure 14 was used to obtain the bottom hole gas influx rates in the simulation. The real-time surface casing pressure measured using the data monitoring system before and after the zone of interest being opened was used as the outlet boundary condition. Some other important parameters in the wellbore flow simulation were given in Table 2. The comparison is good, showing that the estimated permeability is accurate, and the transient well influx model and multiphase flow model can be used to simulate the transient wellbore flow during underbalanced drilling. It is noted that often there is no need to predict the outlet gas rates when performing the reservoir characterization. The purpose

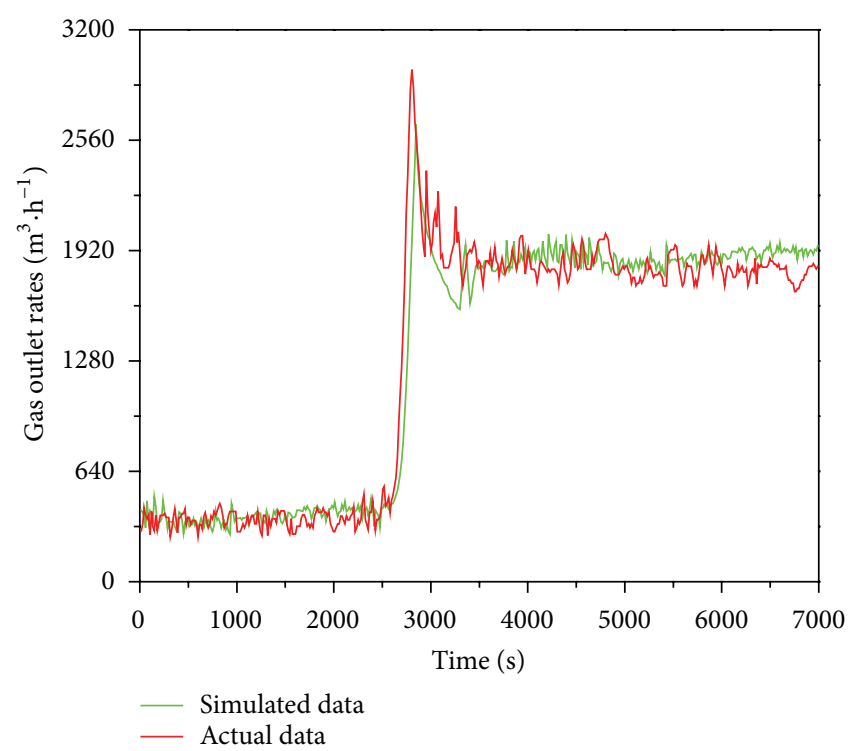

FIGURE 16: Simulated and actual gas outlet rates when the high permeable zone at the depth of $4907 \mathrm{~m}$ was penetrated.

TABLE 2: Some required parameters used in the wellbore flow simulation.

\begin{tabular}{lc}
\hline Well depth of interest, $\mathrm{m}$ & 4907 \\
Injection drilling fluid density, $\mathrm{g} \cdot \mathrm{cm}^{-3}$ & 1.04 \\
Injection drilling fluid rates, $\mathrm{L} \cdot \mathrm{s}^{-1}$ & 18 \\
Injection drilling fluid viscosity & 20 \\
Gas injection rates, $\mathrm{m}^{3} \cdot \mathrm{min}^{-1}$ & 20 \\
Gas injection pressure, $\mathrm{MPa}$ & 15.4 \\
Gas injection temperature, K & 307 \\
Surface temperature, K & 300 \\
\hline
\end{tabular}

of the outlet gas flow rates estimation in Figure 16 was to reversely validate the reservoir characterization method using the estimated permeability profile. In the standard procedure of reservoir characterization, the real-time outlet gas rates and casing pressure measured using the data measuring system are required in the transient wellbore flow simulation as boundary outlet conditions to estimate the bottom hole pressure, which is very important for extracting the permeability of the reservoir zones.

It is noted that a new multiphase flow model was applied to simulate the wellbore flow behavior for aerated drilling without PWD data. Effects of drilling fluid density behavior and wellbore transfer were involved in the new model. The validity and practicability of new model are verified by good agreement between simulated and monitoring results as shown in Figures 16 and 17. Here we discuss the effects of drilling fluid behavior and wellbore transfer on the wellbore flow pressure profile in the annulus. During drilling operations, the annulus fluid, being lower than the formation temperature, receives heat from the formation. In the meantime, the formation near the wellbore is also cooled by the flowing fluid in the annulus. The wellbore temperature in the annulus has a direct bearing on the drilling fluid density and the gas 


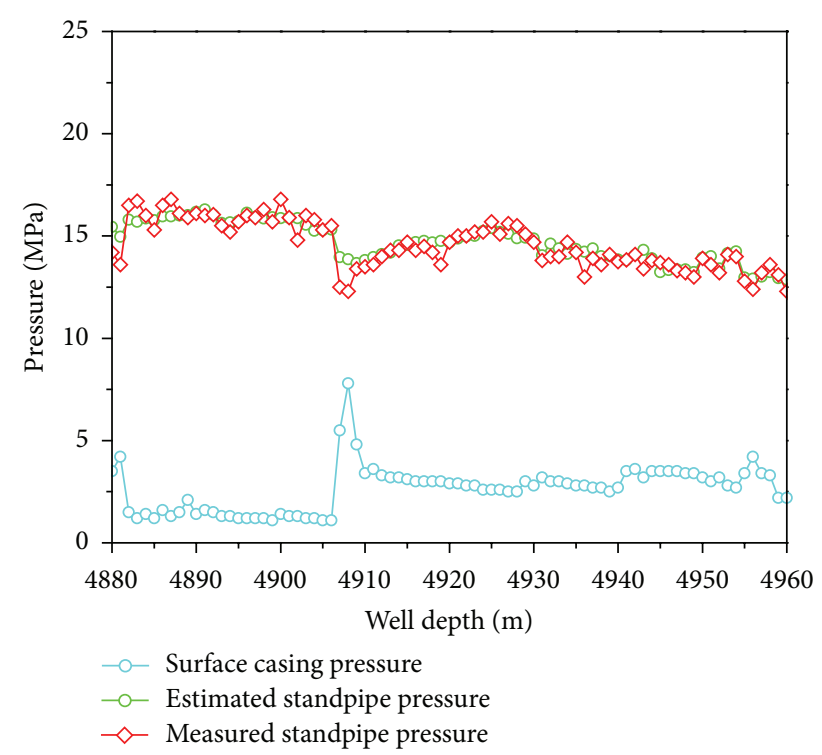

FIGURE 17: Time-averaged measured and estimated standpipe pressure and surface casing pressure when every zone were being penetrated.

compressibility distributions along the annulus, which are very important for the wellbore flow simulation. In this paper, the effects of the drilling fluid density were considered by invoking the temperature and drilling fluid density using the analytical models in (7) and (8), respectively. The estimated wellbore flow pressure profiles in the annulus for different drilling fluid circulation time were plotted in Figure 18. It is noted that the drilling fluid circulation time here was only used for estimating the wellbore temperature profiles in the annulus. In the simulation, we fixed the well depth at $1960 \mathrm{~m}$, outlet drilling fluid rates at $16 \mathrm{~L} \cdot \mathrm{s}^{-1}$, and the casing pressure at $1.8 \mathrm{MPa}$, respectively. The outlet gas rates were assumed at a very low level with $0.01 \mathrm{~m}^{3} \cdot \mathrm{s}^{-1}$ to eliminate the effect of gas compressibility induced by the different temperatures. Some important parameters for drilling fluid can be read in Table 1. In contrast with constant drilling fluid density in traditional model, the simulated results of wellbore pressure using new model are observed being slightly less in the lower part of the wellbore indicated in Figure 18. The results also show that the wellbore pressure profiles are different for different circulation time, especially in bottom hole. We can explain this by inspecting the temperature profiles change in Figure 19. Table 3 reports the values of the thermophysical properties used in the wellbore temperature calculation. Caused by the cooling effect, the rate of wellbore heat transfer diminishes with increasing circulation time. Consequently, the temperature in wellbore declines with circulating and engenders eventually the changes of density profile in Figure 20, which determines the wellbore pressure directly. Data of a water-based drilling fluid from Isambourg et al. [15] reproduced in Table 4 are used here to calculate the drilling fluid density.

The results of the example show that the methodology proposed here can estimate the reservoir pore pressure and

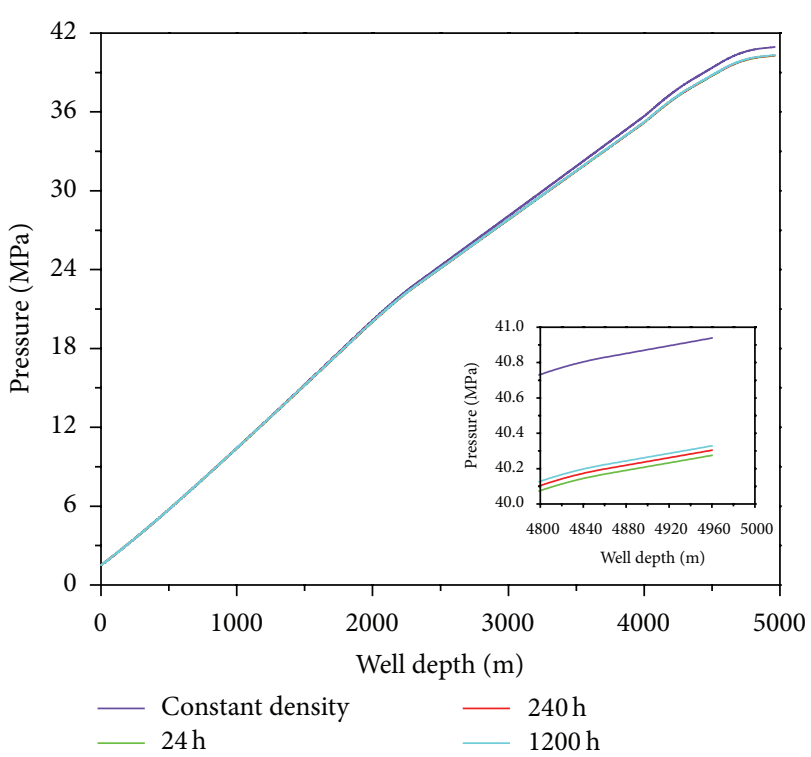

FIGURE 18: Wellbore pressure profiles simulated using traditional model and new model for different circulation time.

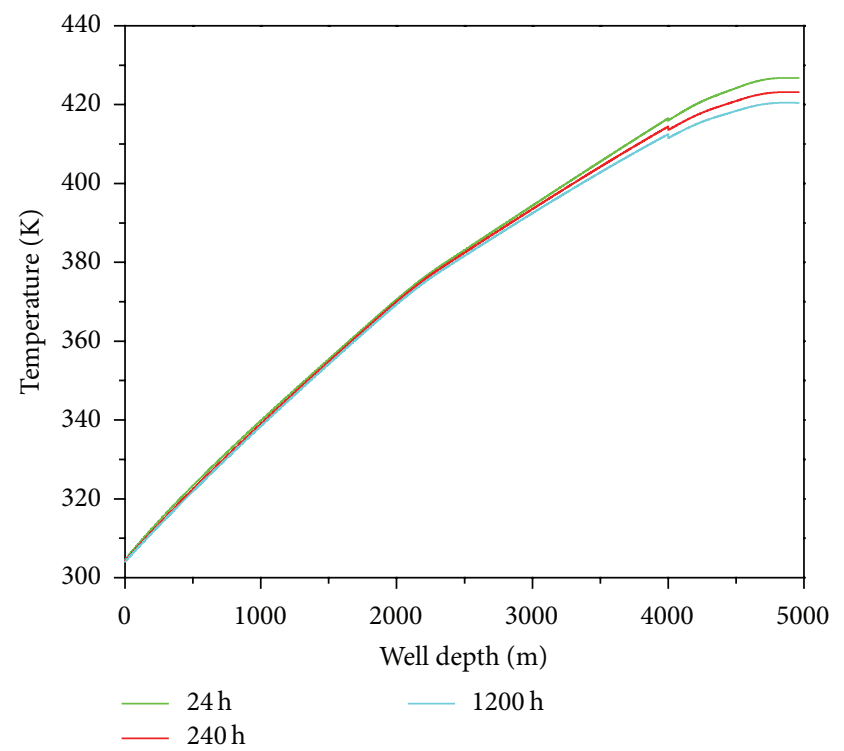

FIGURE 19: Temperature profiles simulated using new wellbore flow model for different circulation time.

the permeability in real time, and the estimated results are able to match the actual data to an acceptable level. However, owing to the complexity of the subject, some essential facets are necessary to provide to improve the quality of the reservoir analysis when performing estimation of permeability and reservoir pore pressure during underbalanced drilling. First and most important, the reservoir pore pressure testing procedure should be initiated immediately once visible gas flow from the reservoir is detected by the real-time data monitoring system, which indicates that gas reservoir has been opened. For the reason that the linear correlation between the inflow and pressure at bottom exists 
TABLE 3: The values of the thermophysical properties for the calculation of temperature profile.

\begin{tabular}{lccccccccc}
\hline$T_{\text {eibh }}$ & $T_{\text {eiwh }}$ & $\begin{array}{c}g_{T} \\
\mathrm{~K} \cdot \mathrm{m}^{-1}\end{array}$ & $\begin{array}{c}g_{c} \\
\mathrm{Kg} \cdot \mathrm{m} \cdot \mathrm{N}^{-1} \cdot \mathrm{sec}^{-2}\end{array}$ & $\begin{array}{c}J \\
\mathrm{~m} \cdot \mathrm{N} \cdot \mathrm{J}^{-1}\end{array}$ & $\begin{array}{c}w \\
\mathrm{~kg} \cdot \mathrm{s}^{-1}\end{array}$ & $\begin{array}{c}k_{e} \\
\mathrm{~W} \cdot \mathrm{m}^{-1} \cdot \mathrm{K}^{-1}\end{array}$ & $\begin{array}{c}C_{p} \\
\mathrm{~J} \cdot \mathrm{kg}^{-1} \cdot \mathrm{K}^{-1}\end{array}$ & $\begin{array}{c}h_{c} \\
\mathrm{~W} \cdot \mathrm{m}^{-2} \cdot \mathrm{K}^{-1}\end{array}$ & $\begin{array}{c}K_{c e m} \\
\mathrm{~W} \cdot \mathrm{m}^{-1} \cdot \mathrm{K}^{-1}\end{array}$ \\
\hline 427 & 303 & 0.03 & 1.00 & 1.00 & 39.82 & 1.44 & 1674.72 & 9.09 & 4.02 \\
\hline
\end{tabular}

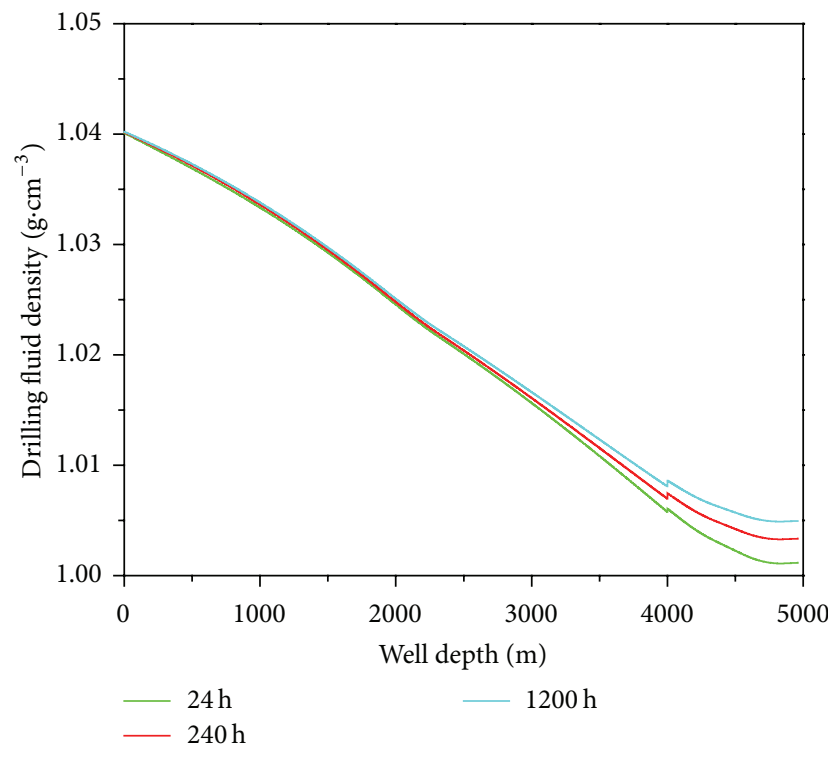

Figure 20: Drilling fluid density profile simulated using new wellbore flow model for different circulation time.

TABLE 4: Empirical constants used in the drilling fluid density calculation (from Isambourg et al. [15]).

\begin{tabular}{lcccc}
\hline$\gamma_{p} \cdot 10^{10}$ & $\gamma_{p p} \cdot 10^{19}$ & $\gamma_{T} \cdot 10^{4}$ & $\gamma_{T T} \cdot 10^{7}$ & $\gamma_{p T} \cdot 10^{13}$ \\
$\mathrm{~Pa}^{-1}$ & $\mathrm{~Pa}^{-2}$ & $\mathrm{~K}^{-1}$ & $\mathrm{~K}^{-2}$ & $\mathrm{~K}^{-1} \mathrm{~Pa}^{-1}$ \\
\hline 2.977 & -2.293 & -1.957 & -16.838 & 0.686 \\
\hline
\end{tabular}

only at the earliest hours of transient inflow, it is hard to acquire accurate estimation of the pore pressure once the best opportunity is missed. Moreover, it is important to maintain the wellbore in underbalance conditions while the reservoir is being penetrated, and the underbalance should be small and relatively stable. The fluids can flow into the wellbore from reservoir and be circulated out from the bottom hole only when the well is drilled underbalance. This is the fundamental premise of the reservoir characterization. The variable underbalance introduces a further complication in the reservoir analysis and produces less accurate estimated results of the permeability. Thus, the underbalance should be kept relatively stable by changing gas, drilling fluid injection rates, or regulating the choke valve. For better estimation of the permeability and well control, low underbalance is also needed. In addition, keeping constant and low penetration rates is a benefit when performing reservoir characterization during underbalanced drilling. For drilling operation, the penetration rates are relatively easy to control by regulating artificially bit-weight in real time.

\section{Conclusion}

In this study, a methodology for estimating reservoir characterization during underbalanced drilling of horizontal wells has been presented. The main reservoir characterization considered here is the reservoir pore pressure and permeability profiles. The methodology is established using a multiphase wellbore flow model merged with a transient well influx model of a horizontal well on the basis of the realtime data monitoring system for aerated drilling and liquidbased underbalanced drilling. The methodology is applied to estimate reservoir pore pressure and permeability. An important aspect of the methodology presented is that we use an improved method to identify the reservoir pore pressure based on the Kneissl's methodology using a different testing procedure.

This methodology has been applied in approximately 10 wells in China. The estimated reservoir pore pressure and permeability are compared with the actual values from well test data and show a good agreement. Owing to the introduction of the models simulating the drilling fluid density behavior and wellbore heat transfer, the multiphase wellbore flow model can be used to estimate the wellbore behavior more accurately, which is very critical for reservoir characterization during aerated underbalanced drilling.

\section{Appendices}

\section{A. Closure Relationships of the Transient Wellbore Flow Model}

A.1. Drag Forces. In this paper, the drag force acting on a gas particle under steady state conditions can be expressed as follows:

$$
F_{d g}=\frac{3}{8} \alpha_{g} \rho_{l} C_{d g} \frac{\left(u_{g}-u_{l}\right)\left|u_{g}-u_{l}\right|}{R_{p g}}
$$

where $C_{d g}$ is the drag coefficient, given by Ishii and Mishima [35] as the following expressions.

For the bubbly flow,

$$
\begin{gathered}
C_{d g}=\frac{4 R_{p g}}{3} \sqrt{\frac{g\left(\rho_{g}-\rho_{l}\right)}{\sigma_{s}}}\left[\frac{1+17.67\left[f\left(\alpha_{g}\right)\right]^{6 / 7}}{18.67 f\left(\alpha_{g}\right)}\right]^{2}, \\
f\left(\alpha_{g}\right)=\left(1-\alpha_{g}\right)^{1.5},
\end{gathered}
$$

where $R_{p g}$ is the gas particle ratio and $\sigma_{s}$ is the gas-liquid interfacial tension, given by Park et al. [31]:

$$
\sigma_{s}=-0.3 \rho_{l}\left(u_{g}-u_{l}\right)^{2}
$$


According to the work of Lahey [36], the bubble radius, $R_{p g}$, is given by

$$
R_{p g}=\left[\left(\frac{2}{32}\right)\left(\frac{\alpha_{g} V}{\pi}\right)\right]^{1 / 3},
$$

where $V$ is the total volume of every numerical node.

For the slug flow,

$$
C_{d g}=9.8\left(1-\alpha_{g}\right)^{3} .
$$

In this paper, the flow patterns are confirmed using the flow pattern transition criteria from the work of Barnea [37].

A.2. Virtual Mass Force. The virtual mass force expresses the momentum exchange caused by relatively accelerated motion. According to Lahey [36], the most common virtual mass force terms for gas phase can be expressed as

$$
F_{v m}=\alpha_{g} \rho_{l} C_{v m}\left(\frac{\partial u_{g}}{\partial t}-\frac{\partial u_{w}}{\partial t}+u_{g} \frac{\partial u_{g}}{\partial z}-u_{l} \frac{\partial u_{l}}{\partial z}\right),
$$

where $C_{v m}$ denotes the virtual mass coefficient of gas phase, given by Ishii and Mishima [35]:

for the bubbly flow,

$$
C_{v m}=\frac{1}{2} \alpha_{g} \frac{1+2 \alpha_{g}}{1-\alpha_{g}},
$$

for the slug flow,

$$
C_{v m}=5 \alpha_{g}\left[0.66+0.34\left(\frac{1-d_{t b} / L_{t b}}{1-d_{t b} / 3 L_{t b}}\right)\right],
$$

where $d_{t b}$ and $L_{t b}$ are, respectively, the long bubble diameter and length of the bubble Taylor, shown in Figure 21. Two parameters can be calculated according the work of Kaya [38].

A.3. Wall Shear Force. In the present paper, the wall shear forces in both bubbly flow and slug flow are discussed. For the bubbly flow, the wall shear force for gas phase is neglected, and the liquid wall shear stress is presented by Wongwised et al. [39] as follows:

$$
\Gamma_{l w}=\frac{0.046}{2} \rho_{l} u_{l}\left|u_{l}\right|\left(\frac{u_{l} d}{v_{l}}\right)^{-0.2} .
$$

Then the liquid wall shear force can be given by

$$
F_{w l}=\frac{\Gamma_{l w} S_{l}}{A}=\frac{0.046 S_{l}}{2 A} \rho_{l} u_{l}\left|u_{l}\right|\left(\frac{u_{l} d}{v_{l}}\right)^{-0.2}
$$

where $A$ is the cross sectional area of the pipe, $S_{l}$ is the liquidwall wetted perimeter, and $d$ is the diameter of the pipe.

For the slug flow, the effect of gas wall shear is no longer neglected. According to the work of Cazarez-Candia et al.

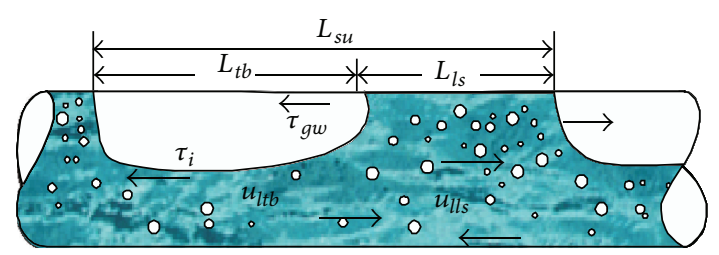

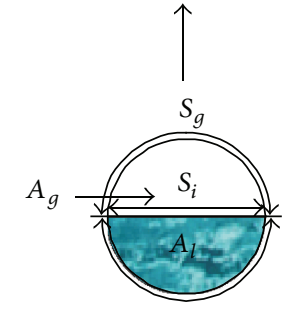

$S_{l}$

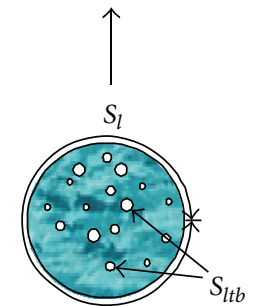

$A_{l}$
FIGURE 21: A schematic of key geometrical parameters in horizontal slug flow.

[40], the wall shear forces for gas and liquid phase are calculated, respectively, as

$$
\begin{gathered}
F_{w g}=\frac{\Gamma_{g w} S_{g} \psi_{l}}{4 A_{g}}+\frac{\Gamma_{g i} S_{i}}{4 A_{g}} \frac{L_{t b}}{L_{s u}}, \\
F_{w l}=\frac{\Gamma_{l w}}{4 L_{s u}}\left(\frac{S_{l} L_{l s}}{A_{l}}+\frac{S_{l t b} L_{t b}}{A_{l t b}}\right)+\frac{\Gamma_{l i} S_{i}}{4 A_{l}} \frac{L_{t b}}{L_{s u}},
\end{gathered}
$$

where $A$ is the area, $S$ is the perimeter, and $\Gamma$ is the shear stress. Parameters $L_{l s}, L_{s u}$ are slug and slug unit lengths, respectively. The parameter $\psi_{1}$ is used to modify the model according to the deviation angle. The subscripts $g, l, i$, and $w$ denote gas, liquid, interface, and wall, respectively. In the same way, the above geometrical parameters according to the region in Figure 21 can be calculated using the means in the Kaya's paper [38].

Shear stresses, for angles from $0^{\circ}$ to $45^{\circ}$, are given by Issa and Kempf [41]:

$$
\begin{gathered}
\Gamma_{g w}=\frac{f_{g} \rho_{g} u_{g}^{2}}{2}, \quad \Gamma_{l w}=\frac{f_{l} \rho_{l} u_{1}^{2}}{2}, \\
\Gamma_{l i}=\frac{f_{i} \rho_{g}\left(u_{g}-u_{l}\right)^{2}}{2},
\end{gathered}
$$

where $f$ is friction factor, can be given by:

$$
\begin{gathered}
f_{g}= \begin{cases}\frac{16}{\mathrm{Re}_{g}} & \text { for } \mathrm{Re}_{g} \leq 2300 \\
0.046 \mathrm{Re}_{g}^{-0.2} & \text { for } \mathrm{Re}_{g}>2300,\end{cases} \\
f_{l}= \begin{cases}\frac{24}{\mathrm{Re}_{l}} & \text { for } \mathrm{Re}_{l} \leq 2300 \\
0.0262\left(\alpha_{l} \mathrm{Re}_{l}\right)^{-0.139} & \text { for } \mathrm{Re}_{l}>2300,\end{cases} \\
f_{i}= \begin{cases}\frac{16}{\mathrm{Re}_{g}} & \text { for } \mathrm{Re}_{i} \leq 2300 \\
0.046 \mathrm{Re}_{i}^{-0.2} & \text { for } \mathrm{Re}_{i}>2300 .\end{cases}
\end{gathered}
$$


Gas, liquid, and interfacial Reynolds numbers are given, respectively, by

$$
\begin{gathered}
\operatorname{Re}_{l}=\frac{d_{l} u_{l} \rho_{l}}{\mu_{l}}, \quad \operatorname{Re}_{g}=\frac{d_{g} u_{g} \rho_{g}}{\mu_{g}}, \\
\operatorname{Re}_{i}=\frac{d_{g}\left(u_{g}-u_{l}\right) \rho_{g}}{\mu_{g}},
\end{gathered}
$$

where $d_{l}, d_{g}$ are the liquid and gas hydraulic diameter, respectively, given as follows:

$$
d_{l}=\frac{4 A_{l}}{S_{l}}, \quad d_{g}=\frac{4 A_{g}}{S_{g}+S_{i}} .
$$

For deviation angle over $45^{\circ}$, the liquid wall shear stress is given by

$$
\Gamma_{l w}=\frac{f_{l} \rho_{l} u_{1}^{2}}{2 d_{l}} \pi d,
$$

where the friction factor is given by the following:

for laminar flow,

$$
f_{l}=\frac{16}{\mathrm{Re}_{l}},
$$

for turbulent flow,

$$
f_{l}=0.079 \mathrm{Re}_{l}^{-0.25},
$$

where

$$
\operatorname{Re}_{l}=\frac{d u_{l} \rho_{l}}{\mu_{l}}
$$

\section{B. Parameters of $(7)$}

The inverse relaxation distance $\xi$ is defined by

$$
\xi=\frac{C_{p} w}{2 \pi}\left(\frac{k_{e}+r_{t o} U_{t o} T_{D}}{r_{t o} U_{t o} k_{e}}\right),
$$

where $w$ is total mass flow rate, $r_{\text {to }}$ is outside radius of drill string, $k_{e}$ is formation conductivity, $U_{t o}$ is overall heat transfer coefficient, and $T_{D}$ is dimensionless temperature. The expression for $U_{t o}$ can be obtained from

$$
U_{t o}=\left[\frac{1}{h_{c}}+\frac{r_{t o} \ln \left(r_{w b} / r_{c o}\right)}{k_{c e m}}\right],
$$

where $h_{c}$ is convective heat transfer coefficient for annulus fluid, $r_{w b}$ is outside radius of wellbore, $r_{c o}$ is outside radius of wellbore, and $k_{c e m}$ is cement conductivity.

The value of dimensionless temperature can be obtained using the following algebraic approximation presented by Hasan and Kabir [42]:

$$
T_{D}=\left\{\begin{array}{c}
\left(1.1281 \sqrt{t_{D}}\right) \times\left(1-0.3 \sqrt{t_{D}}\right) \\
\text { for } 10^{-10} \leq t_{D} \leq 1.5 \\
\left(0.4063+0.5 \ln t_{D}\right) \times\left(1+\frac{0.6}{t_{D}}\right) \\
\text { for } t_{D}>1.5,
\end{array}\right.
$$

where $t_{D}$ is dimensionless time.
The undisturbed formation temperature, $T_{e i}$, is generally assumed to vary linearly with depth, given as follows:

$$
T_{e i}=T_{e i b h}-g_{T} z,
$$

where $T_{\text {eibh }}$ is undisturbed formation temperature at the bottom hole, which can be easily obtained by invoking the undisturbed formation temperature at the wellhead, $T_{\text {eiwh }}$.

In this work, we use the empirical expression developed by Sagar et al. [43] to estimate the value of $\varphi$ as follows:

$$
\begin{aligned}
\varphi= & -0.002978+1.006 \times 10^{-6} p_{w h} \\
& +1.906 \times 10^{-4} w-1.047 \times 10^{-6} F_{g l} \\
& +3.229 \times 10^{-5} \mathrm{API}+0.004009 \gamma_{g}-0.3551 g_{T},
\end{aligned}
$$

where $F_{g l}$ is the ratio of gas and liquid and $\gamma_{g}$ is gas specific gravity.

\section{Conflict of Interests}

The authors declare that there is no conflict of interests regarding the publication of this paper.

\section{Acknowledgments}

The authors are grateful for the support of the National Natural Science Foundation of China (no. 51104124, no. 51204140, and Grant no. 51134004), Major state science and technology special project of China (no. 2011ZX05021-003), and Ph.D. Programs Foundation of Ministry of Education of China (Grant no. 20125121110001).

\section{References}

[1] S. P. Smith, G. A. Gregory, N. Munro, and M. Muqeem, "Application of multiphase flow methods to horizontal underbalanced drilling," Journal of Canadian Petroleum Technology, vol. 39, no. 10, pp. 52-60, 2000.

[2] K. A. Fattah, S. M. El-Katatney, and A. A. Dahab, "Potential implementation of underbalanced drilling technique in Egyptian oil fields," Journal of King Saud University-Engineering Sciences, vol. 23, pp. 49-66, 2011.

[3] E. H. Vefring, G. Nygaard, K. K. Fjelde, R. J. Lorentzen, G. Nævdal, and A. Merlo, "Reservoir characterization during underbalanced drilling: methodology, accuracy, and necessary data," in Proceedings of the SPE Annual Technical Conference and Exhibition, San Antonio, Tex, USA, September-October 2002, Paper SPE 77530.

[4] E. H. Vefring, G. Nygaard, R. J. Lorentzen, G. Nœvdal, and K. K. Fjelde, "Reservoir characterization during underbalanced drilling (UBD): methodology and active tests," SPE Journal, vol. 11, no. 2, pp. 181-192, 2006.

[5] C. B. Kardolus and C. P. J. W. van Kruijsdijk, "Formation testing while underbalanced drilling," in Proceedings of the SPE Annual Technical Conference and Exhibition, pp. 521-528, San Antonio, Tex, USA, October 1997.

[6] C. P. J. W. van Kruijsdijk and R. J. W. Cox, "Testing while underbalanced drilling: horizontal well permeability profiles," 
in Proceedings of the SPE European Formation Damage Conference, Paper SPE 54717, The Hague, The Netherlands, May-June 1999.

[7] L. Larsen and F. Nilsen, "Inflow predictions and testing while underbalanced drilling," in Proceedings of the SPE Annual Technical Conference and Exhibition, Houston, Tex, USA, October 1999, Paper SPE56684.

[8] F. Azar-Nejad, "Formation evaluation while underbalanced drilling of horizontal wells with coiled tubing technology," in Proceedings of the CSPG and Petroleum Society Joint Convention, Digging Deeper, Finding a Better Bottom Line, Paper SPE99-53, Alberta, Canada, June 1999.

[9] J. L. Hunt and S. Rester, "Reservoir characterization during underbalanced drilling: a new model," in Proceedings of the SPE/CERI Gas Technology Symposium, Paper SPE 59743, Calgary, Canada, April 2000.

[10] J. L. Hunt and S. Rester, "Multilayer reservoir model enables more complete reservoir characterization during underbalanced drilling," in Proceedings of the SPE/SPE Underbalanced Technical Conference and Exhibition, pp. 25-26, Houston, Tex, USA, 2003, Paper SPE 81638.

[11] D. Biswas, P. V. Suryanarayana, P. J. Frink, and S. Rahman, "An improved model to predict reservoir characteristics during underbalanced drilling," in Proceedings of the SPE Annual Technical Conference and Exhibition, pp. 1111-1121, Denver, Colo, USA, October 2003, Paper SPE 84176.

[12] W. Kneissl, "Reservoir characterization whilst underbalanced drilling," in Proceedings of the SPE/IADC Drilling Conference, Amsterdam, The Netherlands, February 2001, Paper SPE/IADC 67690.

[13] W. Kneissl and Y. Kuhn de Chizelle, "A method of determining properties relating to an underbalanced well," Patent Application 0024331.1.

[14] G. Stewart, S. Lakshminarayanan, J. Villatoro, and S. Boutalbi, "Variable rate UBD production data facilitates reservoir characterization," in Proceedings of the SPE/IADC Managed Pressure Drilling and Underbalanced Operations Conference and Exhibition, pp. 32-43, Kuala Lumpur, Malaysia, February 2010.

[15] P. Isambourg, B. T. Anfinsen, and C. Marken, "Volumetric behavior of drilling muds at high pressure and high temperature," in Proceedings of the European Petroleum Conference, pp. 157-165, Milan, Italy, October 1996.

[16] G. Aithoff, A. A. Arian, A. B. Kavaipatti, G. L. Varsamis, and L. T. Wisniewski, "MWD ultrasonic caliper advanced detection techniques," in Proceedings of the the SPWLA 39th Annual Logging Symposium, May 1998.

[17] H. Li, G. Li, Y. Meng, G. Shu, K. Zhu, and X. Xu, "Attenuation law of MWD pulses in aerated drilling," Petroleum Exploration and Development, vol. 39, no. 2, pp. 250-255, 2012.

[18] L. A. Carlsen, G. Nygaard, and R. Time, "Utilizing instrumented stand pipe for monitoring drilling fluid dynamics for improving automated drilling operations," in Proceedings of the 1st IFAC Workshop on Automatic Control of Offshore Oil and Gas Production (ACOOG '12), pp. 217-222, Trondheim, Norway, June 2012.

[19] A. D. Spalding and D. Middleton, "Optimum reception in an impulsive interference environment-part II: incoherent reception," IEEE Transactions on Communications, vol. 25, no. 9, pp. 924-934, 1977.
[20] R. T. Lahey Jr. and D. A. Drew, "The three-dimensional time and volume averaged conservation equations of two-phase flow," Advances in Nuclear Science and Technology, vol. 20, no. 1, pp. $1-69,1989$.

[21] A. R. Hasan and C. S. Kabir, "Aspects of wellbore heat transfer during two-phase flow," SPE Production \& Facilities, vol. 9, no. 3, pp. 211-216, 1994.

[22] I. N. Alves, F. J. S. Alhanati, and O. Shoham, "A unified model for predicting flowing temperature distribution in wellbores and pipelines," SPE Production Engineering, vol. 7, no. 4, pp. 363-367, 1992.

[23] E. Karstad and B. S. Aadnoy, "Density behavior of drilling fluids during high pressure high temperature drilling operations," in Proceedings of the IADC/SPE Asia Pacific Drilling Technology, Paper SPE 47806, Jakarta, Indonesia, September 1998.

[24] H. Cho, S. N. Shah, and S. O. Osisanya, "A three-segment hydraulic model for cuttings transport in coiled tubing horizontal and deviated drilling," Journal of Canadian Petroleum Technology, vol. 41, no. 6, pp. 32-39, 2002.

[25] J. Li and S. Walker, "Sensitivity analysis of hole cleaning parameters in directional wells," SPE Journal, vol. 6, no. 4, pp. 356363, 2001.

[26] G. Espinosa-Paredes and O. Cazarez-Candia, "Two-region average model for cuttings transport in horizontal wellbores I: transport equations," Petroleum Science and Technology, vol. 29, no. 13, pp. 1366-1376, 2011.

[27] G. Espinosa-Paredes and O. Cazarez-Candia, "Two-region average model for cuttings transport in horizontal wellbores II: interregion conditions," Petroleum Science and Technology, vol. 29, no. 13, pp. 1377-1386, 2011.

[28] L. Zhou, R. M. Ahmed, S. Z. Miska, N. E. Takach, M. Yu, and M. B. Pickell, "Experimental study and modeling of cuttings transport with aerated mud in horizontal wellbore at simulated downhole conditions," in Proceedings of the SPE Annual Technical Conference and Exhibition, pp. 1051-1062, Houston, Tex, USA, September 2004, Paper SPE 90038.

[29] R. J. Avila, E. J. Pereira, S. Z. Miska, and N. E. Takach, "Correlations and analysis of cuttings transport with aerated fluids in deviated wells," SPE Drilling and Completion, vol. 23, no. 2, pp. 132-141, 2008.

[30] L. Zhou, "Hole cleaning during underbalanced drilling in horizontal and inclined wellbore," SPE Drilling and Completion, vol. 23, no. 3, pp. 267-273, 2008.

[31] J. W. Park, D. A. Drew, and R. T. Lahey Jr., "The analysis of void wave propagation in adiabatic monodispersed bubbly two-phase flows using an ensemble-averaged two-fluid model," International Journal of Multiphase Flow, vol. 24, no. 7, pp. 12051244, 1998.

[32] N. Petalas and K. Aziz, "A mechanistic model for multiphase flow in pipes," Journal of Canadian Petroleum Technology, vol. 39, no. 6, 13 pages, 2000.

[33] A. C. V. M. Lage, Two-phase flow models and experiments for low-head and underbalanced drilling [Ph.D. thesis], Stavanger University. College, Stavanger, Norway, 2000.

[34] C. P. J. W. van Kruijsdijk, "Semianalytical modeling of pressure transient in fractured reservoirs," in Proceedings of the SPE Annual Technical Conference and Exhibition, Houston, Tex, USA, October 1988, Paper SPE 18169. 
[35] M. Ishii and K. Mishima, "Two-fluid model and hydrodynamic constitutive relations," Nuclear Engineering and Design, vol. 82, no. 2-3, pp. 107-126, 1984.

[36] R. T. Lahey, Boiling Heat Transfer: Modern Developments and Advances, Elsevier, Amsterdam, The Netherlands, 1992.

[37] D. Barnea, "A unified model for predicting flow-pattern transitions for the whole range of pipe inclinations," International Journal of Multiphase Flow, vol. 13, no. 1, pp. 1-12, 1987.

[38] A. S. Kaya, Comprehensive mechanistic modeling of two-phase flow in deviated wells [M.S. thesis], The University of Tulsa, Tulsa, Okla, USA, 1998.

[39] S. Wongwises, A. Pornsee, and E. Siroratsakul, "Gas-wall shear stress distribution in horizontal stratified two-phase flow," International Communications in Heat and Mass Transfer, vol. 26, no. 6, pp. 849-860, 1999.

[40] O. Cazarez-Candia, O. C. Benítez-Centeno, and G. EspinosaParedes, "Two-fluid model for transient analysis of slug flow in oil wells," International Journal of Heat and Fluid Flow, vol. 32, no. 3, pp. 762-770, 2011.

[41] R. I. Issa and M. H. W. Kempf, "Simulation of slug flow in horizontal and nearly horizontal pipes with the two-fluid model," International Journal of Multiphase Flow, vol. 29, no. 1, pp. 69-95, 2003.

[42] A. R. Hasan and C. S. Kabir, "Heat transfer during twophase flow in wellbores-part I. Formation temperature," in Proceedings of the the SPE Annual Technical Conference and Exhibition, vol. 22866, Dallas, Tex, USA, 1991.

[43] R. Sagar, D. R. Doty, and Z. Schmidt, "Predicting temperature profiles in a flowing well," SPE Production Engineering, vol. 6, no. 4, pp. 441-448, 1991. 


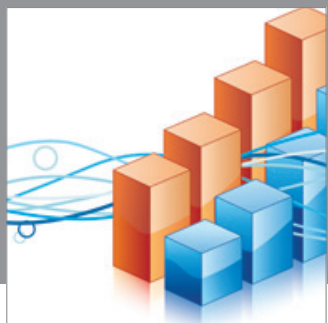

Advances in

Operations Research

mansans

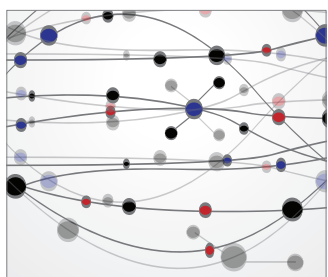

The Scientific World Journal
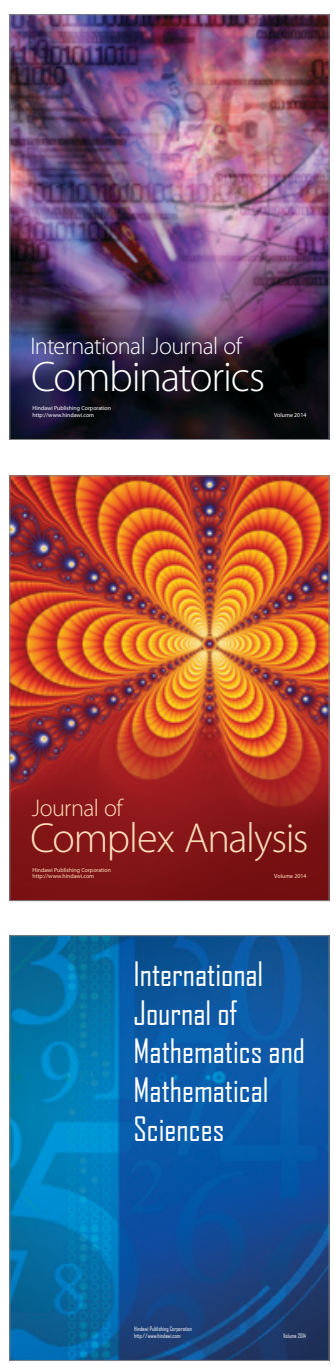
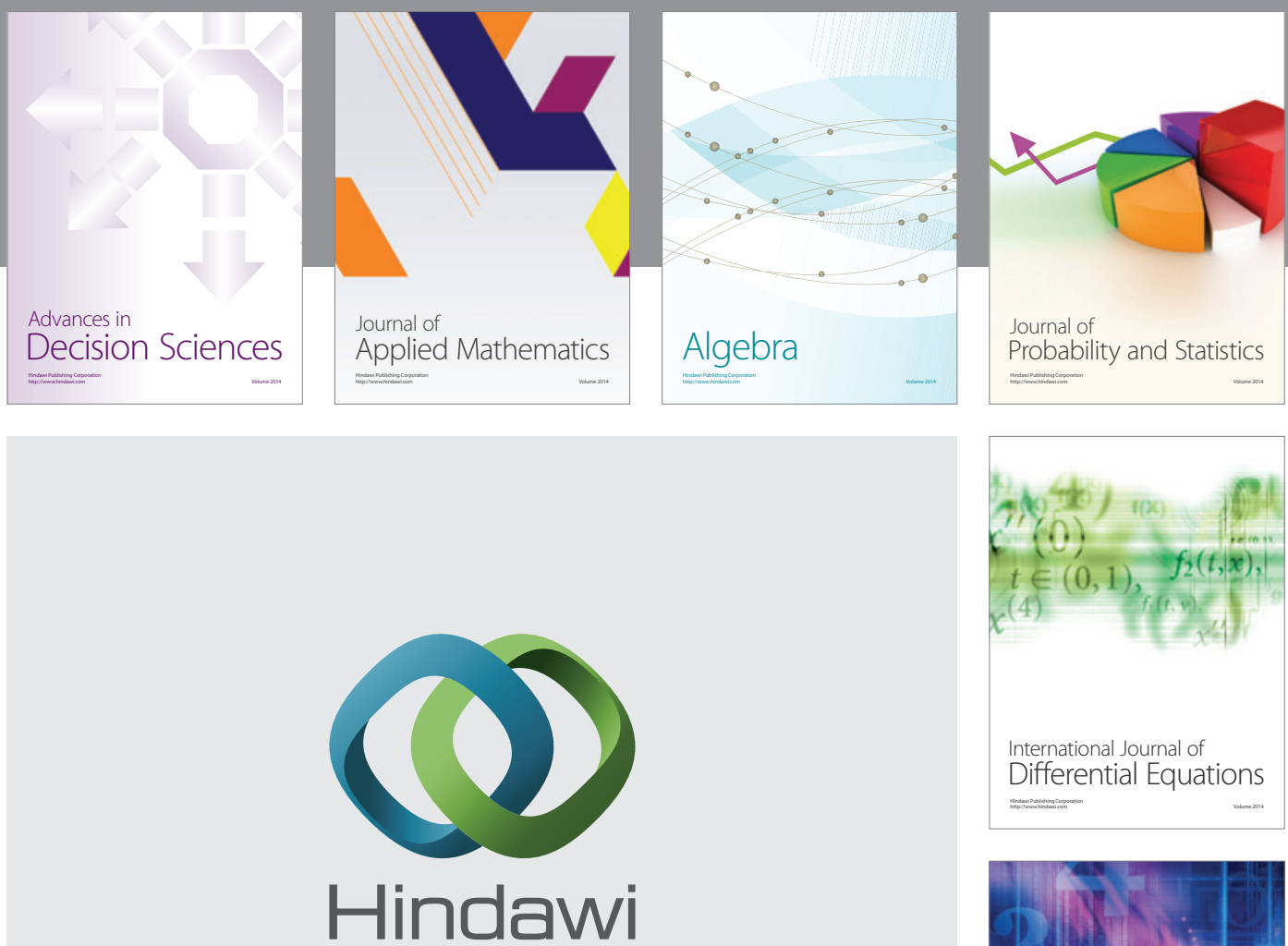

Submit your manuscripts at http://www.hindawi.com
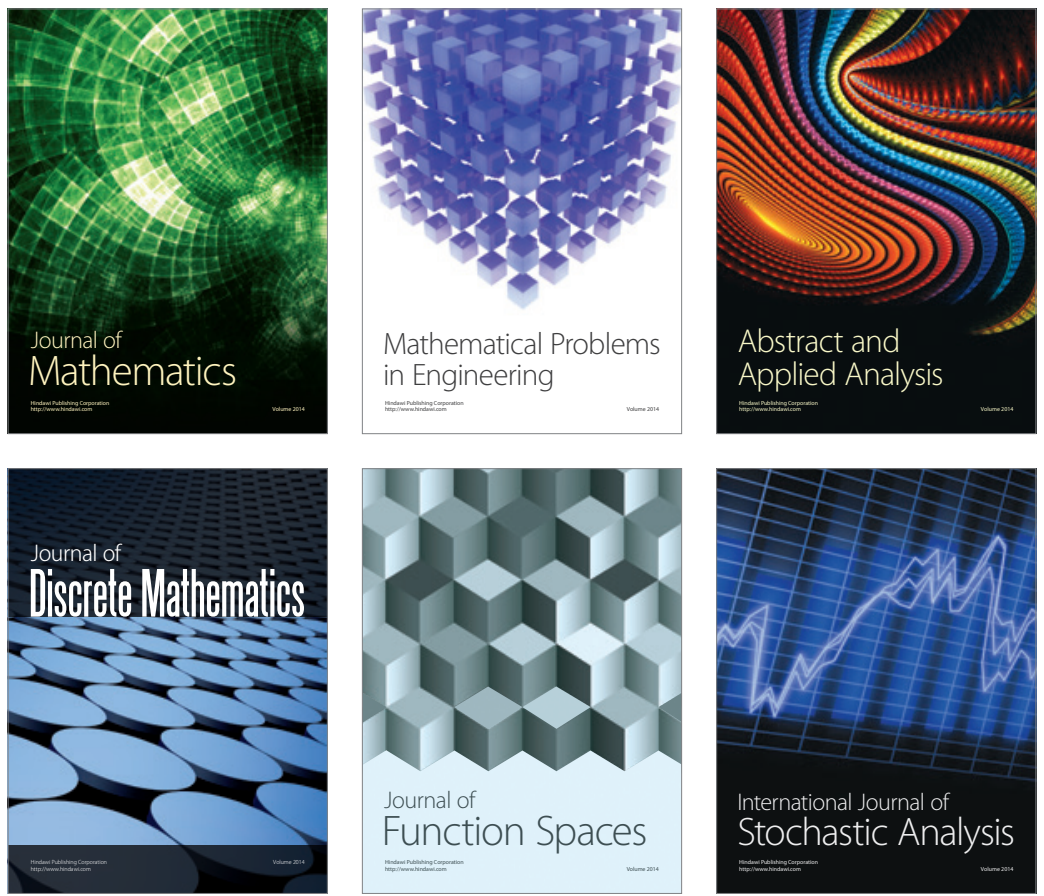

Journal of

Function Spaces

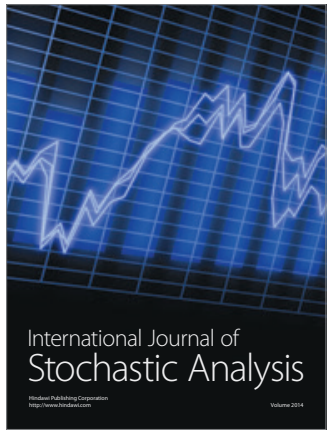

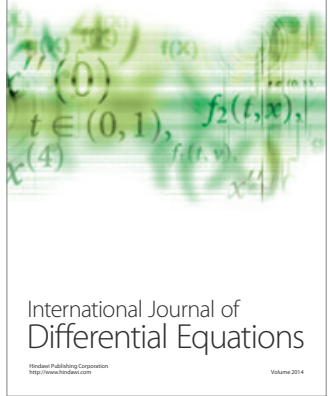
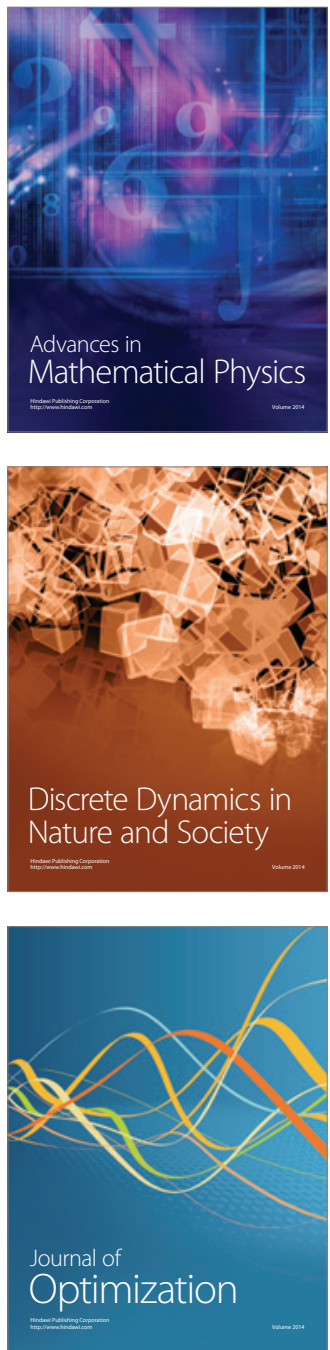